\title{
Reference Evapotranspiration Changes: Sensitivities to and Contributions of Meteorological Factors in the Heihe River Basin of Northwestern China (1961-2014)
}

\author{
Chaoyang Du, ${ }^{1,2}$ Jingjie Yu, ${ }^{1}$ Ping Wang, ${ }^{1}$ and Yichi Zhang ${ }^{1}$ \\ ${ }^{1}$ Key Laboratory of Water Cycle and Related Land Surface Processes, Institute of Geographic Sciences and Natural Resources Research, \\ Chinese Academy of Sciences, Beijing 100101, China \\ ${ }^{2}$ University of Chinese Academy of Sciences, Beijing 100049, China
}

Correspondence should be addressed to Jingjie Yu; yujj@igsnrr.ac.cn

Received 2 August 2015; Accepted 5 November 2015

Academic Editor: Jan Friesen

Copyright (c) 2016 Chaoyang Du et al. This is an open access article distributed under the Creative Commons Attribution License, which permits unrestricted use, distribution, and reproduction in any medium, provided the original work is properly cited.

\begin{abstract}
This paper investigates reference evapotranspiration $\left(\mathrm{ET}_{0}\right)$ changes, sensitivities to and contributions of meteorological factors in the Heihe River Basin (arid and inland region). Results show that annual $\mathrm{ET}_{0}$ over the whole basin has increasing trend $\left(2.01 \mathrm{~mm} \cdot 10 \mathrm{yr}^{-2}\right)$ and there are significant increasing spatial variations from the upper $\left(753 \mathrm{~mm} \mathrm{yr}^{-1}\right)$ to the lower $\left(1553 \mathrm{~mm} \mathrm{yr}^{-1}\right)$ regions. Sensitivity analysis indicates that relative humidity is the most sensitive factor for seasonal and annual ET ${ }_{0}$ change, and the influence is negative. The sensitivity of minimum temperature is the weakest and negative. Contribution analysis shows that the main contributors to $\mathrm{ET}_{0}$ changes are aerodynamic factors rather than radiative factors. This study could be helpful to understand the response of ecoenvironment to the meteorological factors changes in the Heihe River Basin.
\end{abstract}

\section{Introduction}

Evapotranspiration is an excellent indicator of hydroclimatic change and the response of water management, food security, and ecoenvironment [1]. Among different evapotranspiration terms, such as actual evapotranspiration $\left(\mathrm{ET}_{a}\right)$, potential evapotranspiration $\left(\mathrm{ET}_{p}\right)$, pan evaporation $\left(E_{\mathrm{pan}}\right)$, and reference evapotranspiration $\left(\mathrm{ET}_{0}\right), E_{\mathrm{pan}}$ and $\mathrm{ET}_{0}$ are often used as surrogates of $\mathrm{ET}_{p}$ to reflect the evaporation capability in a specific region. Because $\mathrm{ET}_{p}$ and $\mathrm{ET}_{0}$ are dependent only on meteorological condition not underlying surface and are measurable or calculable, they are important hydroclimatic indicators for reflecting regional water-energy balance changes and the effect of climate change. Spatiotemporal variations of $\mathrm{ET}_{0}$ in different climatic regions have been globally reported over the past decades [2, 3]. Many regions have experienced significant decreasing trends of $E_{\text {pan }}$ or $\mathrm{ET}_{0}$, such as the US [4], China [5], Canada [6], Australia [7], India [8], Japan [9], and Romania [10]. However, $\mathrm{ET}_{0}$ changes with significant positive trends have been reported in other regions, such as the Mediterranean region [11], Iran [12], Spain [13], and Serbia [14]. Moreover, the interannual fluctuations of $\mathrm{ET}_{0}$ for some regions are very significant; $\mathrm{ET}_{0}$ may increase during one period but decrease during the next period $[5,7]$. Therefore, the temporal variations of $\mathrm{ET}_{0}$ are complex and diverse in different climatic zones. Reasons for the different temporal variations of $\mathrm{ET}_{0}$ in different climatic zones need to be explored in further detail.

The causes of $\mathrm{ET}_{0}$ changes in many regions have been studied. First, the effects of different methods on $\mathrm{ET}_{0}$ changes have been discussed in different climatic zones. Popular methods for $\mathrm{ET}_{0}$ calculation mainly include $\mathrm{FAO} \mathrm{P}-\mathrm{M}$, Priestley-Taylor, Hargreaves, Makkink, Blaney-Criddle, and Samani-Hargreaves methods [15]. Comparisons showed that FAO P-M performs better among the different methods due to having the clear physical meaning and is recommended as a standard method for the $\mathrm{ET}_{0}$ calculation $[16,17]$. Second, a sensitivity coefficient was used to investigate the effects of meteorological factors on $\mathrm{ET}_{0}$ change [18-20]. Most studies showed that aerodynamic factors are the major factors in 
different regions. For example, air temperature, wind speed, and relative humidity have stronger effects on $\mathrm{ET}_{0}$ change in Spain [20]. Air temperature and wind speed are the dominant variables influencing $\mathrm{ET}_{0}$ in Iran [12]. Air temperature is the most sensitive variable to $\mathrm{ET}_{0}$ change in India [21]. Similar results have also been found in some regions of China, in which wind speed, air temperature, and vapor pressure deficit are the major sensitive factors for $\mathrm{ET}_{0}$ change in such areas as the Loess Plateau Region [22], the Liaohe delta [23], the Tibet Plateau [24], the Changjiang River Basin [19], and the Haihe River Basin [25]. Some studies proposed a close agreement between changes in $\mathrm{ET}_{0}$ and solar energy in Greece [26], Korea [27], and the Yellow River Basin [28]. Sensitivity analysis could only describe the responses of $\mathrm{ET}_{0}$ to changes in individual factor. However, it cannot determine how much the impact of each meteorological factor on $\mathrm{ET}_{0}$ change is.

The Heihe River basin (HRB), the second largest inland river basin in northwestern China, consists of three regions with different landscapes and climate conditions, where the upper mountainous region is semiarid and natural with little human interference, the middle region is dry and intensively irrigated plain, and the lower region is an extremely dry Gobi desert plain. The spatial variation of $\mathrm{ET}_{0}$ in such basin may supply more information of regional response to the climate. The previous studies only reported the spatiotemporal variations of $\mathrm{ET}_{0}[29,30]$ at a given period, but there is no common understanding of $\mathrm{ET}_{0}$ change so far due to different data time series. The aim of this paper is to clarify the effect of meteorological factors on $\mathrm{ET}_{0}$ change by comprehensively analyzing the sensitivity of $\mathrm{ET}_{0}$ change and contributions of meteorological factors in the HRB using reliable and complete daily meteorological data from 16 stations for the period 1961-2014. This paper will determine (1) the spatial pattern and temporal trends of $\mathrm{ET}_{0}$ for the HRB, (2) the sensitivity of $\mathrm{ET}_{0}$ to meteorological factors, and (3) the contributions of the meteorological factors to $\mathrm{ET}_{0}$ change.

\section{Study Area and Data}

2.1. Study Area. As shown in Figure 1, the drainage map and the basin border of the HRB are extracted using a $90 \mathrm{~m}$ resolution digital elevation model (DEM) data from the Shuttle Radar Topography Mission (SRTM) website of the NASA (http://srtm.csi.cgiar.org/SELECTION/inputCoord .asp) (basin length: $820 \mathrm{~km}$; total area: $143,000 \mathrm{~km}^{2}$; elevation: 870-5545 m).

The HRB is divided into three regions according to basin characteristics, shown in Figure 1. The upper mountainous region belongs to the cold and semiarid mountain zone with an elevation from 2000 to $5000 \mathrm{~m}$, annual mean temperature of less than $2^{\circ} \mathrm{C}$, pan evaporation of $700 \mathrm{~mm} \mathrm{yr}^{-1}$, and precipitation of $350-400 \mathrm{~mm} \mathrm{yr}^{-1}$. The middle region is the main irrigation zone and residential area with more than $90 \%$ of the total population of the basin; it has a precipitation of $100-250 \mathrm{~mm} \mathrm{yr}^{-1}$ and pan evaporation of $2000 \mathrm{~mm} \mathrm{yr}^{-1}$. The lower region is covered by the arid Gobi

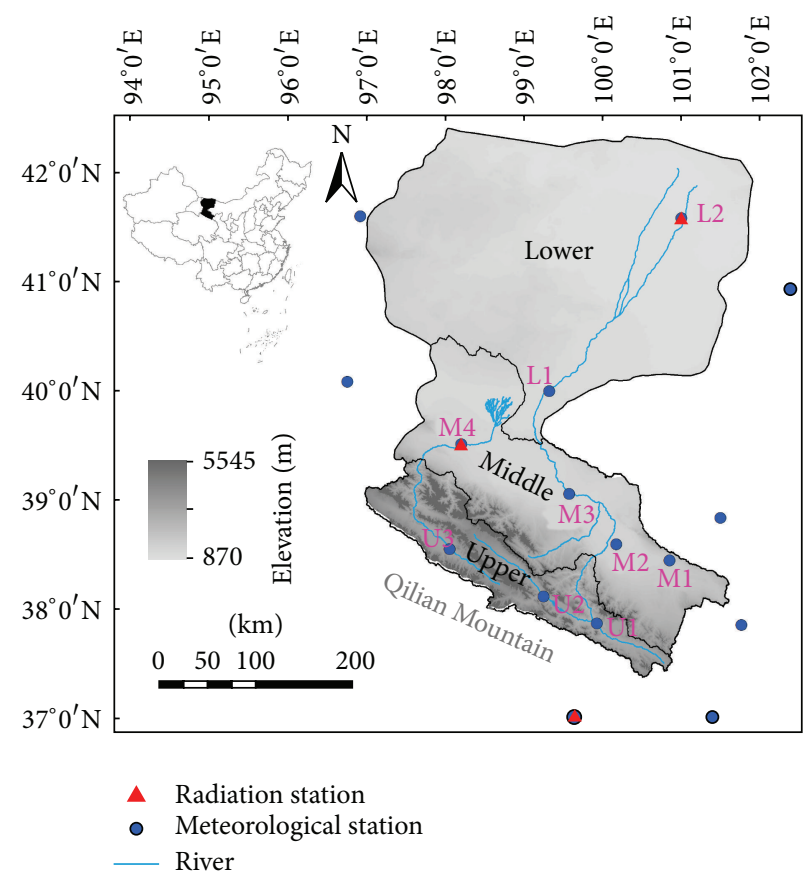

FIGURE 1: Location of the HRB and spatial distribution of the meteorological and radiation stations. $\mathrm{U}, \mathrm{M}$, and $\mathrm{L}$ represent the upper, middle, and lower regions in the basin, respectively.

desert in the north of the basin with an elevation of 870$1500 \mathrm{~m}$ and is characterized by an extremely arid climate, with pan evaporation of $3500 \mathrm{~mm} \mathrm{yr}^{-1}$ and precipitation of $10-$ $50 \mathrm{~mm} \mathrm{yr}^{-1}$.

2.2. Data. In this study, daily meteorological data of 16 stations from 1961 to 2014 in and around the HRB are available from the National Climatic Centre of the China Meteorological Administration. The three solar radiation stations correspond to the upper, the middle, and the lower region (Figure 1). The data set includes daily observations of atmospheric pressure, maximum and minimum air temperatures at $2 \mathrm{~m}$ height $\left(T_{\max }, T_{\min }\right)$, relative humidity at $2 \mathrm{~m}$ height (RH), daily sunshine duration, pan evaporation measured using a metal pan, $20 \mathrm{~cm}$ in diameter and $10 \mathrm{~cm}$ high, installed $70 \mathrm{~cm}$ above the ground, and wind speed measured at $10 \mathrm{~m}$ height which was transformed to wind speed at $2 \mathrm{~m}$ height (WS) by the wind profile relationship from Chapter 3 of the FAO paper 56 [16]. In addition, the three radiation stations were used to calibrate the Angström parameters of extraterrestrial radiation reaching the earth on clear days in the FAO P-M equation. The spatial patterns of the meteorological factors, $\mathrm{ET}_{0}$, and sensitivity coefficients were obtained by the inverse distance weight (IDW) interpolation method.

In this study, the four seasons of the HRB are defined as spring (from March to May), summer (from June to August), autumn (from September to November), and winter (from December to February). 


\section{Methodology}

3.1. FAO Penman-Monteith Method. The Penman-Monteith method can be used globally to estimate potential evapotranspiration. Allen et al. simplified the Penman-Monteith equation and defined the hypothetical reference grass with an assumed height of $0.12 \mathrm{~m}$, a fixed surface resistance of $70 \mathrm{~s} \mathrm{~m}^{-1}$, and an albedo of 0.23 [16]. This method can provide good and reliable results for $\mathrm{ET}_{0}$ because it is physically based and explicitly incorporates both physiological and aerodynamic parameters and has been accepted as a standard to compare evapotranspiration capability for various climatic regions [31]. Moreover, this method has been successfully applied across the whole of China $[32,33]$. The FAO P-M for calculating daily $\mathrm{ET}_{0}$ is described as

$$
\begin{aligned}
& \mathrm{ET}_{0} \\
& =\frac{0.408 \Delta\left(R_{n}-G\right)+\gamma\left(900 /\left(T_{\text {mean }}+273\right)\right) u_{2}\left(e_{s}-e_{a}\right)}{\Delta+\gamma\left(1+0.34 u_{2}\right)},
\end{aligned}
$$

where $\mathrm{ET}_{0}$ is the reference evapotranspiration $\left(\mathrm{mm} \mathrm{day}^{-1}\right)$, $R_{n}$ is the net radiation at the crop surface $\left(\mathrm{MJ} \mathrm{m}^{-2}\right.$ day $\left.^{-1}\right), G$ is the soil heat flux density $\left(\mathrm{MJ} \mathrm{m}^{-2}\right.$ day $\left.^{-1}\right), T_{\text {mean }}$ is the mean daily air temperature at $2 \mathrm{~m}$ height $\left({ }^{\circ} \mathrm{C}\right), u_{2}$ is the wind speed at $2 \mathrm{~m}$ height $\left(\mathrm{m} \mathrm{s}^{-1}\right), e_{s}$ is the saturation vapor pressure $(\mathrm{kPa})$, $e_{a}$ is the actual vapor pressure $(\mathrm{kPa}), \Delta$ is the slope vapor pressure curve $\left(\mathrm{kPa}^{\circ} \mathrm{C}^{-1}\right), \gamma$ is the psychrometric constant $\left(\mathrm{kPa}^{\circ} \mathrm{C}^{-1}\right)$; the atmospheric pressure used in this study is the measured value. More details regarding the data processing in (1) can be found in FAO paper 56.

In (1), the solar radiation $\left(R_{s}\right)$ is obtained with the following Ångström formula:

$$
R_{s}=\left(a+b \frac{n}{N}\right) R_{a}
$$

where $R_{s}$ is the solar radiation $\left(\mathrm{MJ} \mathrm{m}^{-2}\right.$ day $\left.^{-1}\right), n$ is the actual sunshine duration (hours), $N$ is the maximum possible sunshine duration or daylight hours (hours), $R_{a}$ is the extraterrestrial radiation $\left(\mathrm{MJ} \mathrm{m}^{-2} \mathrm{day}^{-1}\right)$, and $a$ and $b$ are regression constants.

Because of the effects of the atmospheric conditions (humidity, dust) and solar declination (latitude and month) as well as the elevation variations, the Angström values $a$ and $b$ in the HRB were calibrated using the observed radiation data at the three solar radiation stations (Figure 2).

3.2. Trend Analysis. The long-term trends and changes of $\mathrm{ET}_{0}$ and meteorological factors are detected using the linear fitted method:

$$
\widehat{y}=\widehat{a} t+\widehat{b},
$$

where $\hat{y}$ is the fitted trend during a given period and $\widehat{a}$ and $\widehat{b}$ are the estimated regression slope and the regression constant, respectively. Positive slope indicates an increasing trend and negative slope indicates a decreasing trend.

For data sets without seasonality, the significance of a trend is described using the Mann-Kendall (MK) test method
$[34,35]$, which is to statistically assess if there is a monotonic trend of the variable of interest over time [36], whilst the Seasonal Kendall (SK) test is extension of the MK test and is suitable for trend applicable to data sets with seasonality, missing values, and serial correlation over time [37, 38]. The SK test begins by computing the MK test separately for each month or season and then summing the statistic $S_{i}$ and variance $\operatorname{Var}\left(S_{i}\right)$. Following Hirsch et al. [37], the entire sample $X$ is made up of subsamples $X_{1}$ through $X_{12}$ (one for each month), and each subsample $X_{i}$ contains the $n_{i}$ annual values from month $i$ :

$$
\begin{aligned}
X & =\left(X_{1}, X_{2}, \ldots, X_{12}\right), \\
X_{i} & =\left(X_{i 1}, X_{i 2}, \ldots, X_{i 12}\right) .
\end{aligned}
$$

The null hypothesis $H_{0}$ for the SK test is that the $X$ is a sample of independent random variables $\left(x_{i j}\right)$ and that each $X_{1}$ is a subsample of independent and identically distributed random variables over years. The alternative hypothesis $H_{1}$ is that for one or more months the subsample is not distributed identically over years.

According to the MK test, the statistic $S_{i}$ is defined by

$$
S_{i}=\sum_{k=1}^{n_{i}-1} \sum_{j=k+1}^{n_{i}} \operatorname{sign}\left(x_{i j}-x_{i k}\right),
$$

where

$$
\operatorname{sign}(\theta)= \begin{cases}1, & \theta>0 \\ 0, & \theta=0 \\ -1, & \theta<0\end{cases}
$$

Now, the subsample $X_{i}$ satisfies the null hypothesis of Mann's test. Therefore relying on Mann and Kendall we have

$$
\begin{aligned}
& E\left(S_{i}\right)=0 \\
& \operatorname{Var}\left(S_{i}\right) \\
& \quad=\frac{1}{18}\left|n_{i}\left(n_{i}-1\right)\left(2 n_{i}+5\right)-\sum_{t_{i}}^{g_{i}} t_{i}\left(t_{i}-1\right)\left(2 t_{i}+5\right)\right|,
\end{aligned}
$$

where $g_{i}$ is the number of tied groups for the $i$ th month and $t_{i p}$ is the number of data in the $p$ th group for the $i$ th month. $S_{i}$ is normal in the limit as $n_{i} \rightarrow \infty$. The SK test statistic $S$ is given by

$$
S=\sum_{i=1}^{m} S_{i}
$$

where $m$ is the number of months for which data have been obtained over years. The expectation and variance can be derived as follows:

$$
\begin{aligned}
E(S) & =\sum_{i=1}^{m} E\left(S_{i}\right), \\
\operatorname{Var}(S) & =\sum_{i=1}^{m} \operatorname{Var}\left(S_{i}\right)+\sum_{i=1}^{m} \sum_{j=1}^{m} \operatorname{cov}\left(S_{i} S_{j}\right),
\end{aligned}
$$




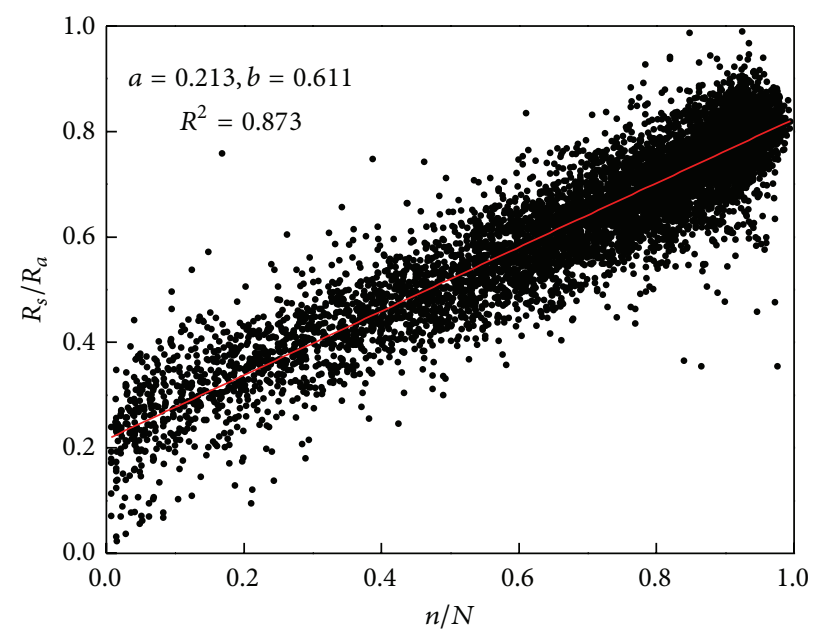

(a)

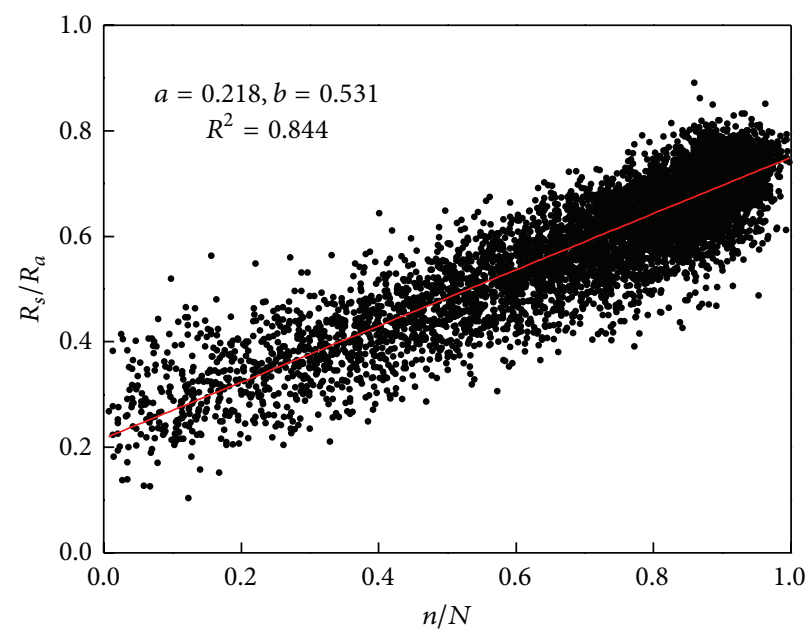

(b)

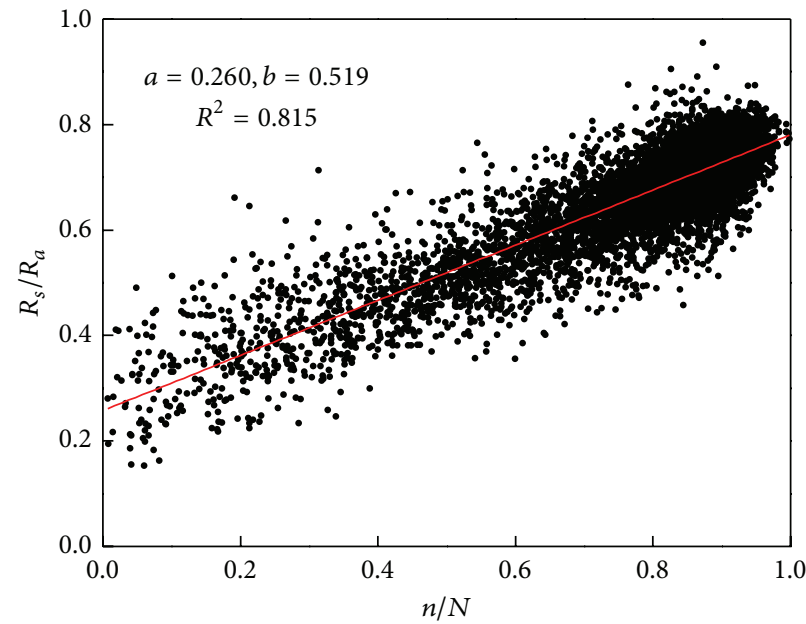

(c)

FIGURE 2: Calibration of the Ångström coefficients for the three radiation stations: (a) Gangcha station in the upper region, (b) Jiuquan station in the middle region, and (c) Ejina station in the lower region.

where $S_{i}$ and $S_{j}(i \neq j)$ are function of independent random variables, so $\operatorname{cov}\left(S_{i} S_{j}\right)=0$.

For $n_{1}>10$, the standard normal deviate $Z$ is estimated by (10) to test the significance of trends:

$$
Z= \begin{cases}\frac{(S-1)}{\sqrt{V(S)}}, & S>0, \\ 0, & S=0, \\ \frac{(S+1)}{\sqrt{V(S)}}, & S<0 .\end{cases}
$$

For the SK test, the null hypothesis $H_{0}$ means that there is no monotonic trend over time; when $|Z|>Z_{1-\alpha / 2}$, the original null hypothesis is rejected; this means that the trend of the time series is statistically significant. In this study, significance level of $\alpha=0.1$ is employed.

3.3. Sensitivity Analysis. Saxton [18] and Smajstrla et al. [39] defined the sensitivity coefficient by drawing a curve of the change of a dependent variable versus the changes of independent variables. For multifactor models (e.g., the FAO $\mathrm{P}-\mathrm{M}$ ), due to different dimensions and ranges of different factors, the ratios of $\mathrm{ET}_{0}$ changes and factors changes cannot be compared. In addition, this approach could introduce errors to understand the response of model behaviors to the factors because of changing one of the factors but holding other factors stationary [27]. To avoid the above two disadvantages, the dimensionless sensitivity coefficient defined by the dimensionless partial derivative with respect to the independent factors is used in this study:

$$
S\left(x_{i}\right)=\lim _{\Delta x_{i} \rightarrow 0}\left(\frac{\Delta \mathrm{ET}_{0} / \mathrm{ET}_{0}}{\Delta x_{i} / x_{i}}\right)=\frac{\partial \mathrm{ET}_{0}}{\partial x_{i}} \cdot \frac{x_{i}}{\mathrm{ET}_{0}},
$$

where $x_{i}$ is the $i$ th meteorological factor and $S\left(x_{i}\right)$ is the dimensionless sensitivity coefficient of reference evapotranspiration related to $x_{i}$. Greve et al. [40] used this method to estimate the effects of variation in meteorological factors and 
measurement error on evaporation change. If the sensitivity coefficient of a factor is positive (negative), $\mathrm{ET}_{0}$ will increase (decrease) as the factor increases. The larger the absolute value of the sensitivity coefficient, the more $\mathrm{ET}_{0}$ is sensitive to a factor.

In this study, the meteorological factors $T_{\max }, T_{\min }, \mathrm{WS}$, $\mathrm{RH}$, and $R_{s}$ are chosen for sensitivity analysis. Sensitivity coefficients $\left(S_{T_{\max }}, S_{T_{\min }}, S_{\mathrm{WS}}, S_{\mathrm{RH}}\right.$, and $\left.S_{R_{s}}\right)$ were calculated on a daily dataset. Monthly and annual average sensitivity coefficients were obtained by average daily values. Regional sensitivity coefficients were obtained by averaging station values.

3.4. Contribution Estimation. Although sensitivity coefficients can reflect the sensitivity of $\mathrm{ET}_{0}$ change to the perturbation of a factor, it cannot describe the contribution of a factor change to $\mathrm{ET}_{0}$ change. Because both of the sensitivity and changes in meteorological factors affected $\mathrm{ET}_{0}$ change, an approach to integrating the sensitivity and changes of meteorological factors is proposed to quantify influence magnitude individual meteorological factors changes to the trends of $\mathrm{ET}_{0}$.

Mathematically, for the function $\mathrm{ET}_{0}=f\left(x_{1}, x_{2}, \ldots, x_{n}\right)$, where $x_{1}, x_{2}, \ldots, x_{n}$ are independent variables, the first order Taylor approximation of the dependent variable $\mathrm{ET}_{0}$ in terms of the independent variables is expressed as

$$
\Delta \mathrm{ET}_{0}=\sum \frac{\partial \mathrm{ET}_{0}}{\partial x_{i}} \cdot \Delta x_{i}+\delta,
$$

where $\Delta \mathrm{ET}_{0}$ is the change of $\mathrm{ET}_{0}$ during a period, $x_{i}$ is the $i$ th meteorological factor, $\Delta x_{i}$ is the change of $x_{i}$ during the same period, $\partial \mathrm{ET}_{0} / \partial x_{i}$ is the partial differential of $\mathrm{ET}_{0}$ with respect to $x_{i}$, and $\delta$ is the Lagrange remainder.

If both sides of (12) are divided by $\overline{\mathrm{ET}_{0}}$ (the average value of $\mathrm{ET}_{0}$ during a period), (12) can be written as

$$
\frac{\Delta \mathrm{ET}_{0}}{\overline{\mathrm{ET}_{0}}}=\sum \frac{\partial \mathrm{ET}_{0}}{\partial x_{i}} \cdot \frac{\Delta x_{i}}{\overline{\mathrm{ET}_{0}}}+\varepsilon,
$$

where $\Delta \mathrm{ET}_{0} / \overline{\mathrm{ET}_{0}}$ is the relative change of $\mathrm{ET}_{0}$ during a given period; $\varepsilon=\delta / \overline{\mathrm{ET}}_{0}$ is the error item, which can be neglected because of its small value.

The first term in the right side of equation is multiplied by $\bar{x}_{i} / \bar{x}_{i} ;(13)$ can be written as

$$
\frac{\Delta \mathrm{ET}_{0}}{\overline{\mathrm{ET}_{0}}}=\sum \frac{\partial \mathrm{ET}_{0}}{\partial x_{i}} \cdot \frac{\bar{x}_{i}}{\overline{\mathrm{ET}_{0}}} \frac{\Delta x_{i}}{\bar{x}_{i}}+\varepsilon,
$$

where $\left(\partial \mathrm{ET}_{0} / \partial x_{i}\right) \cdot\left(\bar{x}_{i} / \overline{\mathrm{ET}_{0}}\right)$ is the average sensitivity coefficient of factor $x_{i}$ during a period, denoted as $\bar{S}_{x i}$. If we let $C\left(x_{i}\right)=\sum \bar{S}_{x i} \cdot\left(\Delta x_{i} / \bar{x}_{i}\right),(14)$ can be written as

$$
\frac{\Delta \mathrm{ET}_{0}}{\overline{\mathrm{ET}_{0}}} \approx \sum C\left(x_{i}\right)
$$

$C\left(x_{i}\right)$ is the relative change in $\mathrm{ET}_{0}$ contributed by $T_{\max }, T_{\min }$, WS, RH, and $R_{s}$.
TABLE 1: Coefficient of determination of monthly $E_{\text {pan }}$ and $\mathrm{ET}_{0}$ for nine meteorological stations.

\begin{tabular}{lccccccccc}
\hline Station & U1 & U2 & U3 & M1 & M2 & M3 & M4 & L1 & L2 \\
\hline$R^{2}$ & 0.945 & 0.939 & 0.966 & 0.969 & 0.973 & 0.959 & 0.968 & 0.965 & 0.986 \\
\hline
\end{tabular}

\section{Results}

4.1. Correlation of $E T_{0}$ and $E_{\text {pan }}$. The coefficients of determination $R$ of monthly $E_{\text {pan }}$ and $\mathrm{ET}_{0}$ for different stations (Table 1 ) are between 0.939 and 0.986 , which means that the monthly $E_{\text {pan }}$ and $\mathrm{ET}_{0}$ have a very close linear relationship in the HRB. Such a close linear relationship suggests that $\mathrm{ET}_{0}$ can be a good estimation using the observed $E_{\text {pan }}$ in the HRB if the regression coefficients are given. Moreover, Figures 3(a) and 3(b) show that monthly and annual $E_{\text {pan }}$ and $\mathrm{ET}_{0}$ both present good linearity. The monthly and annual $R$ values are 0.967 and 0.906 , respectively. And the correlation of monthly $E_{\text {pan }}$ and $\mathrm{ET}_{0}$ appears to be a strong seasonal characteristic and becomes less centralized from winter to summer.

4.2. Evolution and Spatial Pattern of $E T_{0}$ at Different Time Scales. Figure 4 shows the average monthly $\mathrm{ET}_{0}$ change during a year for the whole basin during 1961 and 2014. The mean monthly $\mathrm{ET}_{0}$ is $97.8 \mathrm{~mm} \mathrm{month}^{-1}$ over the whole basin in the last 50 years. Monthly $\mathrm{ET}_{0}$ first increases and then decreases during a year. The peak value occurs in June and July, approximately $177 \mathrm{~mm} \mathrm{month}^{-1}$, whereas the bottom values occur during November and February and are less than $50 \mathrm{~mm} \mathrm{month}^{-1}$. This strong monthly variation has a similar shape feature to the natural change in temperature and solar radiation (Figures 4 and 7 ). In addition, $\mathrm{ET}_{0}$ in summer months differs more dramatically than that in winter months. And the difference between the maximum and the minimum of $\mathrm{ET}_{0}$ reaches $50 \mathrm{~mm}$ in July, whereas the difference in December is only $10 \mathrm{~mm}$. The evaporation capability in summer months accounts for $44 \%$ of annual $\mathrm{ET}_{0}$.

Figure 5 shows the trends of annual and seasonal $\mathrm{ET}_{0}$ for the whole basin from 1961 to 2014. The mean annual $\mathrm{ET}_{0}$ is $1175 \mathrm{~mm} \mathrm{yr}^{-1}$. The increasing trend of annual $\mathrm{ET}_{0}$ is $2.01 \mathrm{~mm} \cdot 10 \mathrm{yr}^{-2}$ over the 54 years and has no statistical significance. Annual $\mathrm{ET}_{0}$ variations exhibit three different phases, which has a significant increasing trend during 19611974 and 1997-2014 but clearly decreases during 1975-1996 at 0.05 levels (Figure 5(e)). The 1961-2014 means of $\mathrm{ET}_{0}$ from spring to winter are $363 \mathrm{~mm} \mathrm{yr}^{-1}, 511 \mathrm{~mm} \mathrm{yr}^{-1}, 220 \mathrm{~mm} \mathrm{yr}^{-1}$, and $81.4 \mathrm{~mm} \mathrm{yr}^{-1}$, respectively. The climatic trends of $\mathrm{ET}_{0}$ in spring and winter are $2.07 \mathrm{~mm} \cdot 10 \mathrm{yr}^{-2}$ and $0.52 \mathrm{~mm} \cdot 10 \mathrm{yr}^{-2}$, respectively, whereas $\mathrm{ET}_{0}$ changes in summer and winter have decreasing trends of $-0.7 \mathrm{~mm} \cdot 10 \mathrm{yr}^{-2}$ and $-0.06 \mathrm{~mm} \cdot 10 \mathrm{yr}^{-2}$.

Table 2 reports the mean values and trends of seasonal and annual $\mathrm{ET}_{0}$ in the three subregions from 1961 to 2014. The seasonal and annual $\mathrm{ET}_{0}$ have gradually increasing spatial gradients from the upper region to the lower region. The mean annual $\mathrm{ET}_{0}$ of the upper, middle, and lower regions are $902 \mathrm{~mm} \mathrm{yr}^{-1}, 1051 \mathrm{~mm} \mathrm{yr}^{-1}$, and $1289 \mathrm{~mm} \mathrm{yr}^{-1}$, 


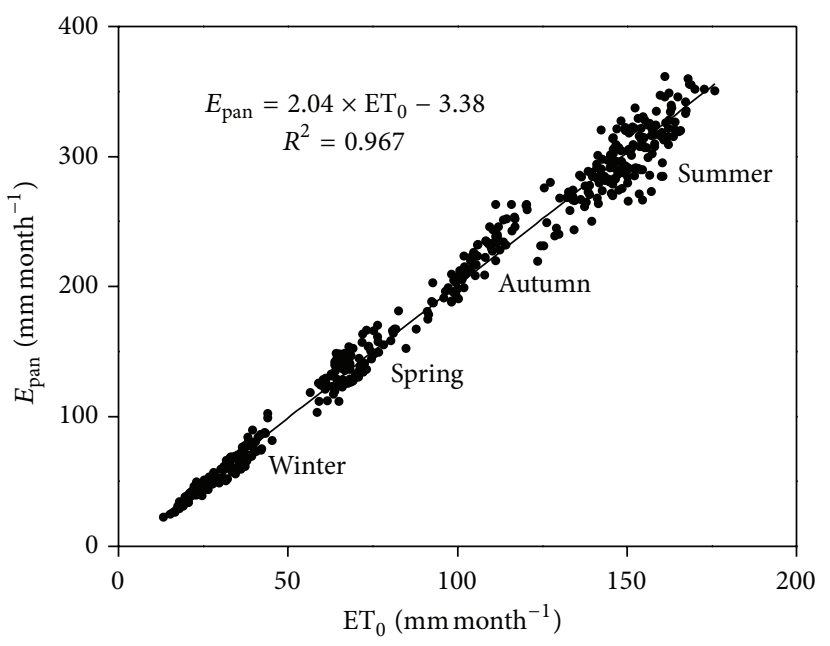

(a)

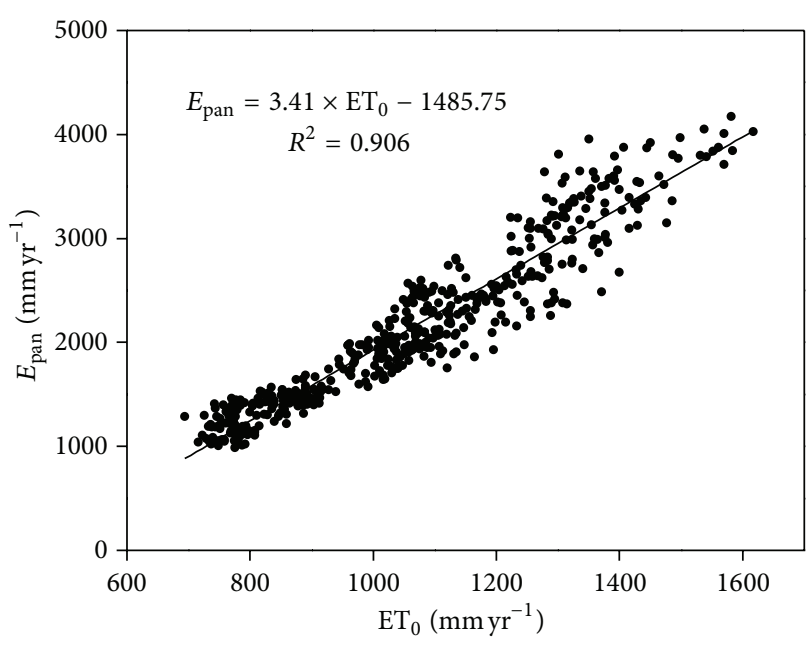

(b)

FIGURE 3: Relationship between $E_{\text {pan }}$ and $\mathrm{ET}_{0}$ at monthly (a) and annual (b) scales for nine meteorological stations from 1961 to 2001.

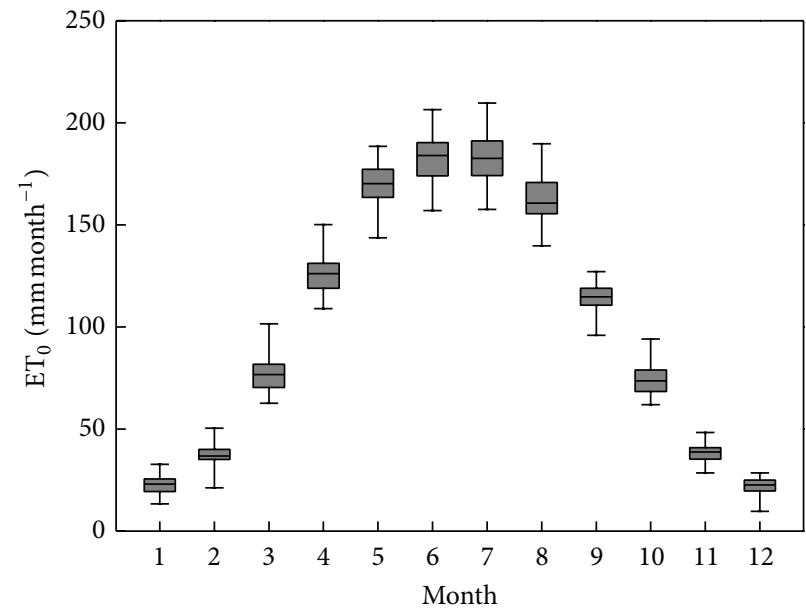

Figure 4: Box and whisker plots of monthly $\mathrm{ET}_{0}$ of the HRB from 1961 to 2014 . The line inside the boxes represents the median, and the upper and lower lines of the boxes indicate the 75th and 25th percentiles, respectively. The upper and lower parts of the whiskers indicate the maximum and the minimum of monthly $\mathrm{ET}_{0}$, respectively.

respectively. The $\mathrm{ET}_{0}$ change in the upper region appears to be a statistically increasing trend at $6.61 \mathrm{~mm} \cdot 10 \mathrm{yr}^{-2}$. The climatic trends of annual $\mathrm{ET}_{0}$ in the middle and lower regions are $2.25 \mathrm{~mm} \cdot 10 \mathrm{yr}^{-2}$ and $0.91 \mathrm{~mm} \cdot 10 \mathrm{yr}^{-2}$, respectively, without statistical significance.

The maximum and minimum values of seasonal $\mathrm{ET}_{0}$ consistently occur in summer and winter, respectively, for the three regions. Whereas the seasonal $\mathrm{ET}_{0}$ trends are different, $\mathrm{ET}_{0}$ for the upper region has significant increasing trends in spring, autumn, and winter, with increasing rates of 2.41 , 1.19 , and $1.54 \mathrm{~mm} \cdot 10 \mathrm{yr}^{-2}$, respectively. Seasonal $\mathrm{ET}_{0}$ has no significant trend for the middle and lower regions.

The spatial patterns of seasonal and annual $\mathrm{ET}_{0}$ in the HRB from 1961 to 2014 are plotted in Figure 6. There are clear spatial gradients for annual $\mathrm{ET}_{0}$ from the upper region to the lower region. The maximum occurs in the lower region and is up to $1553 \mathrm{~mm} \mathrm{yr}^{-1}$ near station L2, and the minimum is found in the upper region and is as low as $757 \mathrm{~mm} \mathrm{yr}^{-1}$ near station $\mathrm{U} 2$ in the upper region.

The spatial variation of seasonal $\mathrm{ET}_{0}$ is smaller than that of annual $\mathrm{ET}_{0}$. The $\mathrm{ET}_{0}$ changes in spring, summer, and autumn have similar spatial features. The $\mathrm{ET}_{0}$ changes only in summer have a clear spatial pattern, ranging from $300 \mathrm{~mm} \mathrm{yr}^{-1}$ to $700 \mathrm{~mm} \mathrm{yr}^{-1}$ over the whole basin. Variations of $\mathrm{ET}_{0}$ in the other three seasons have very small spatial gradients across the whole basin. The spatial difference in $\mathrm{ET}_{0}$ in spring is between $232 \mathrm{~mm} \mathrm{yr}^{-1}$ and $472 \mathrm{~mm} \mathrm{yr}^{-1}$, with a SD of $49 \mathrm{~mm} \mathrm{yr}^{-1}$, and the $\mathrm{ET}_{0}$ variation in the autumn ranges from $145 \mathrm{~mm} \mathrm{yr}^{-1}$ to $290 \mathrm{~mm} \mathrm{yr}^{-1}$, with a SD of $30 \mathrm{~mm} \mathrm{yr}^{-1}$. The spatial distribution of $\mathrm{ET}_{0}$ in winter varies little, and its SD is only $5.8 \mathrm{~mm} \mathrm{yr}^{-1}$ over the whole basin.

4.3. Trends in Meteorological Factors. According to the FAO P-M method described in (1), $T_{\max }, T_{\min }, \mathrm{WS}, \mathrm{RH}$, and $R_{s}$ 


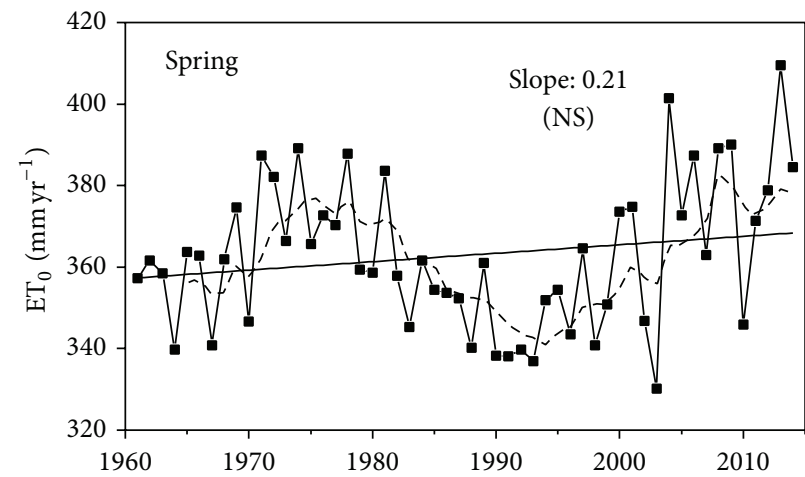

(a)

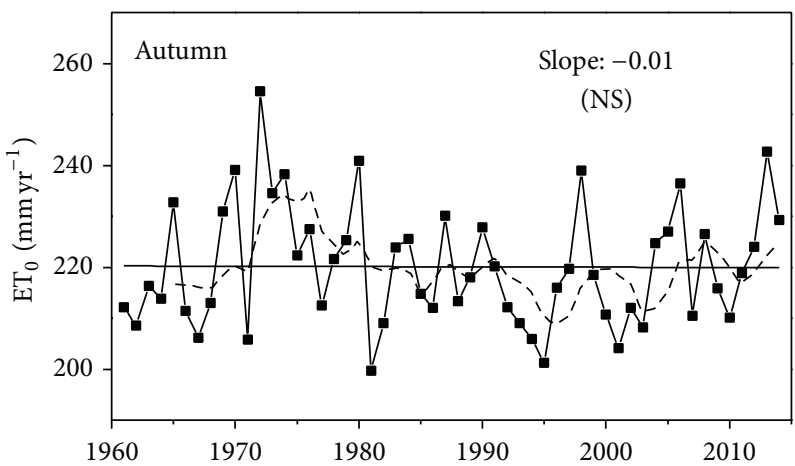

(c)

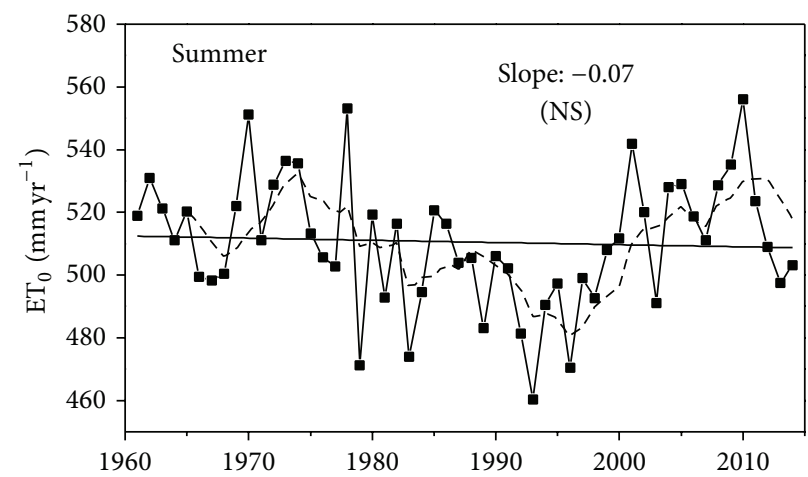

(b)

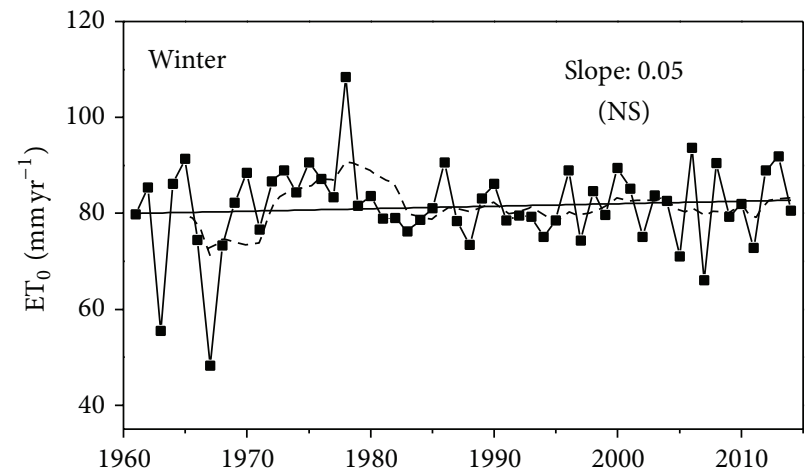

(d)

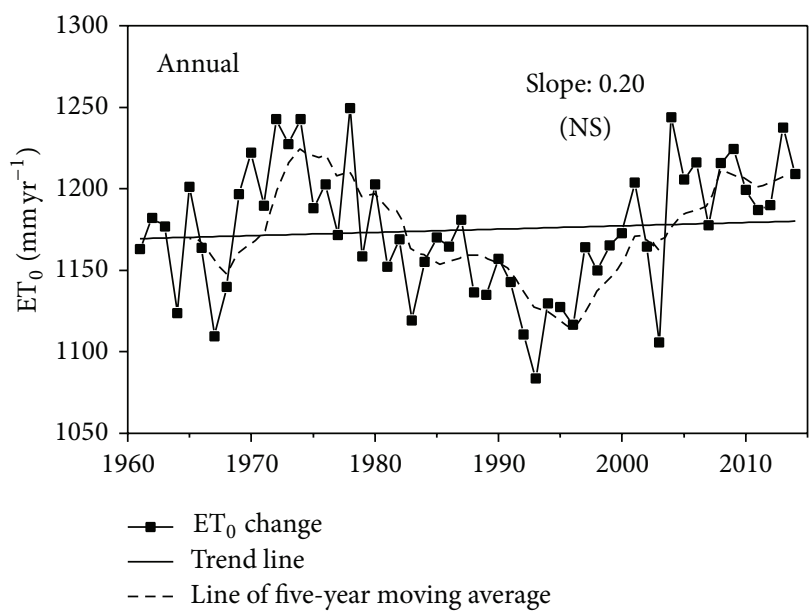

(e)

FIGURE 5: Annual and seasonal $\mathrm{ET}_{0}$ trends for the HRB during 1961 and 2014. NS means not significant at the level of $\alpha<0.05$ by the MK test.

TABLE 2: Means of seasonal and annual $\mathrm{ET}_{0}$ and their trends in the three subregions during 1961-2014.

\begin{tabular}{|c|c|c|c|c|c|c|}
\hline Region & & Annual & Spring & Summer & Autumn & Winter \\
\hline \multirow{2}{*}{ Upper region } & Mean $\left(\mathrm{mm} \mathrm{yr}^{-1}\right)$ & 902 & 280 & 380 & 171 & 71.1 \\
\hline & Trend $\left(\mathrm{mm} \cdot 10 \mathrm{yr}^{-2}\right)$ & $6.61^{*}$ & $2.41^{*}$ & 1.33 & $1.19^{*}$ & $1.54^{*}$ \\
\hline \multirow{2}{*}{ Middle region } & Mean $\left(\mathrm{mm} \mathrm{yr}^{-1}\right)$ & 1051 & 330 & 446 & 196 & 78.6 \\
\hline & Trend $\left(\mathrm{mm} \cdot 10 \mathrm{yr}^{-2}\right)$ & 2.25 & 2.03 & -0.33 & -0.21 & 0.58 \\
\hline \multirow{2}{*}{ Lower region } & Mean $\left(\mathrm{mm} \mathrm{yr}^{-1}\right)$ & 1289 & 395 & 568 & 241 & 84.8 \\
\hline & Trend $\left(\mathrm{mm} \cdot 10 \mathrm{yr}^{-2}\right)$ & 0.91 & 2.02 & -1.31 & -0.26 & 0.31 \\
\hline
\end{tabular}

Note: $*$ means the significance level of 0.1 . 

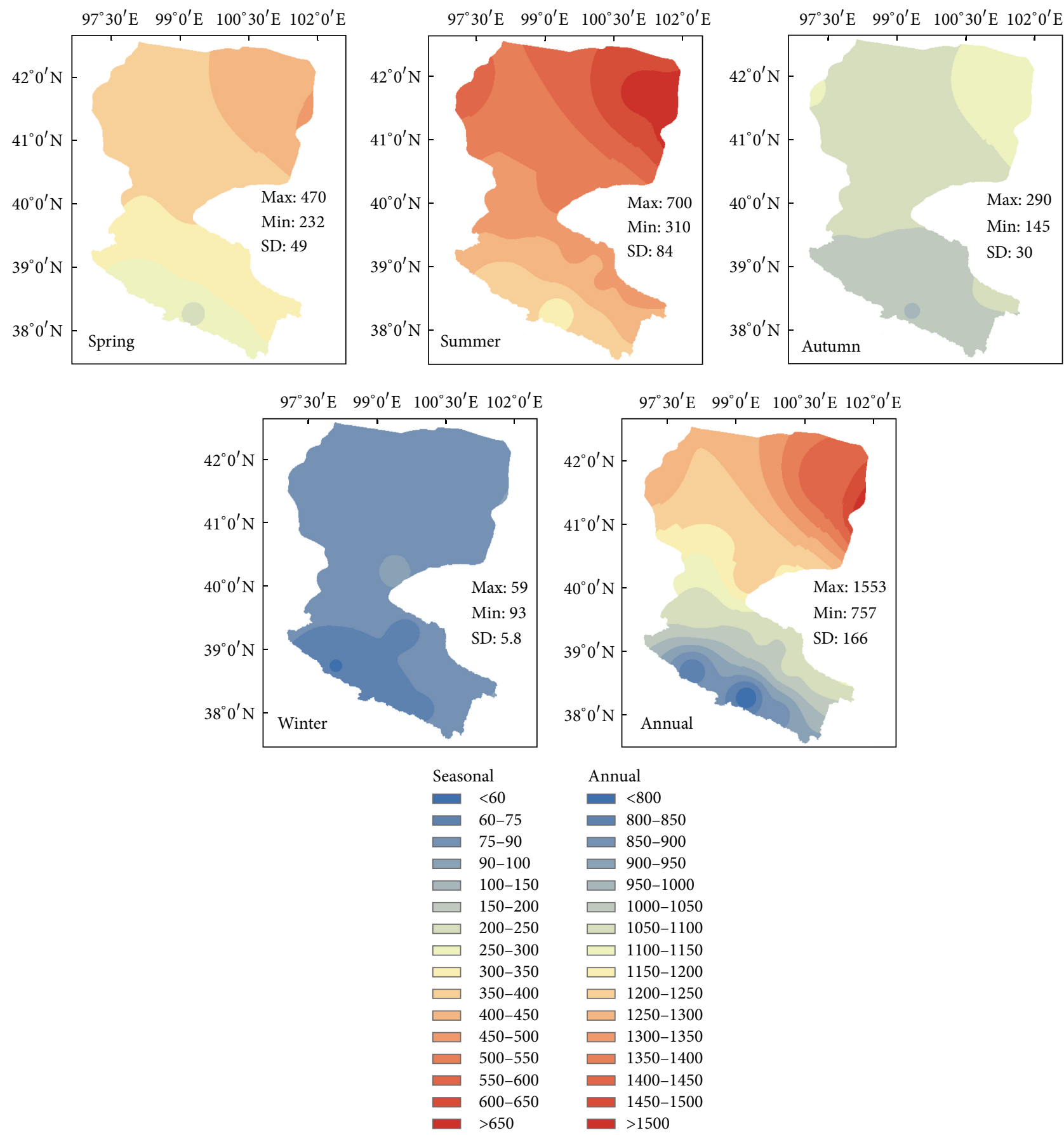

Figure 6: Spatial patterns of the seasonal and annual mean $\mathrm{ET}_{0}$ in the whole HRB from 1961 to 2014 . Max and Min denote the maximum and minimum values, respectively, of $\mathrm{ET}_{0}$ over the whole basin. $\mathrm{SD}$ indicates the standard deviation of the spatial variations of $\mathrm{ET}_{0}$.

are selected as the major meteorological factors having an important influence on $\mathrm{ET}_{0} . T_{\text {mean }}$ (the average of $T_{\max }$ and $\left.T_{\min }\right)$ is a comprehensive indicator for analyzing temperature variation.

Figure 7 shows monthly variations of meteorological factors in the upper, middle, and lower regions and the whole basin during 1961 and 2014. The variations of monthly $T_{\text {mean }}$ and $R_{s}$ are similar to those of monthly $\mathrm{ET}_{0}$ (Figure 4), and their peak values occur in the middle of the year, with a minimum at the ends of the year. The air temperature in the upper region is the smallest over the whole basin, which ranges from $-12.6^{\circ} \mathrm{C}$ month $^{-1}$ to $12.9^{\circ} \mathrm{C} \mathrm{month}^{-1}$. Although the average monthly $T_{\text {mean }}$ in the middle and lower regions are both $8.1^{\circ} \mathrm{C}_{\text {month }}{ }^{-1}$, the maximum value of $T_{\text {mean }}$ in the lower region is larger than that in the middle region, and the minimum value in the lower region is smaller than that in the middle region. Moreover, the standard deviation of monthly $T_{\text {mean }}$ in the middle region is the smallest. 

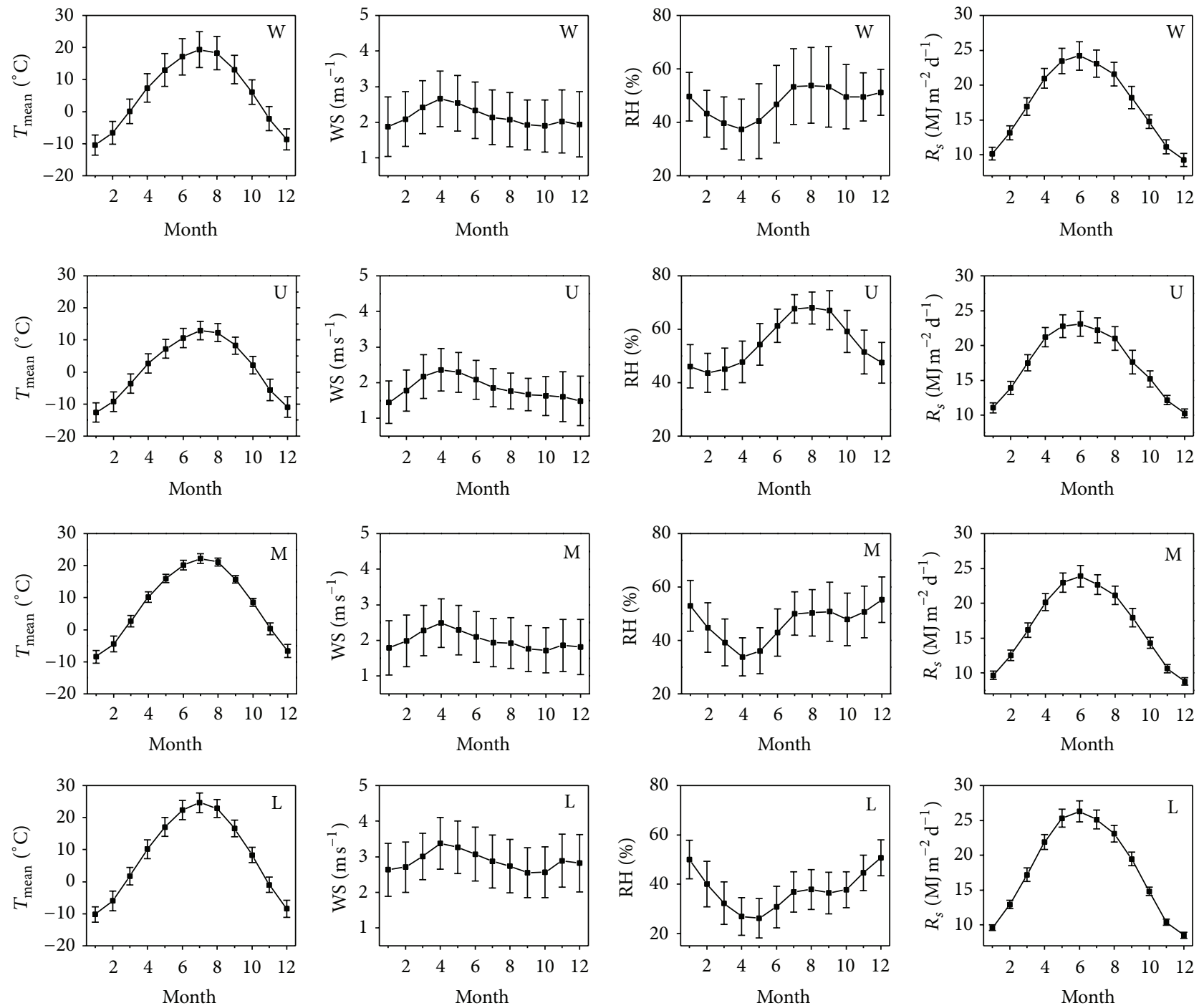

FIGURE 7: Monthly variations of meteorological factors ( $T_{\text {mean }}, \mathrm{WS}, \mathrm{RH}$, and $R_{\mathrm{s}}$ ) in the upper $(\mathrm{U})$, middle $(\mathrm{M})$, and lower $(\mathrm{L})$ regions and the whole basin (W). The 54-year mean (solid line) and standard deviation (error bar) are shown.

The variation of wind speed during a year is relatively small. The peak of monthly WS occurs in April. There are similar variation features of WS for the three subregions. The monthly WS in the lower region is the largest, with an average of $2.8 \mathrm{~m} \mathrm{~s}^{-1}$ month $^{-1}$ during the year, whereas that in the lower region is the smallest, with an average of $1.8 \mathrm{~m} \mathrm{~s}^{-1}$ month $^{-1}$. The higher error bar means that the monthly WS has significant fluctuations during the year.

The monthly $\mathrm{RH}$ from the lower to the upper region gradually increases and the fluctuations of $\mathrm{RH}$ are also substantial. The monthly RH in the upper region increases at first and then decreases, and its peak is during June and August. The monthly RH in the middle and lower regions decreases at first and then increases, and its bottom is in April.

The monthly $R_{s}$ in different regions have the same variation features and standard deviations during the year. The high value of monthly $R_{s}$ is found during June and August, and the low value occurs in winter. The standard deviation during May and August is larger than that from November to February.

Figure 8 shows trends of annual $T_{\text {mean }}$, WS, RH, and $R_{s}$ for the upper, middle, and lower regions and the whole basin during 1961 and 2014. Positive trends of annual $T_{\text {mean }}$ during 1961 and 2014 are detected in the upper, middle, and lower regions and the whole basin, with significant rates of change of $0.32^{\circ} \mathrm{C} \cdot 10 \mathrm{yr}^{-2}, 0.33^{\circ} \mathrm{C} \cdot 10 \mathrm{yr}^{-2}, 0.38^{\circ} \mathrm{C} \cdot 10 \mathrm{yr}^{-2}$, and $0.36^{\circ} \mathrm{C} \cdot 10 \mathrm{yr}^{-2}$, respectively.

The mean annual WS in the lower region is $2.5 \mathrm{~m} \mathrm{~s}^{-1} \mathrm{yr}^{-1}$ and is larger than that in other regions. The interannual oscillations of annual WS for the middle and lower regions and the whole basin are similar and have three phases: two relatively steady periods from 1961 to 1968 and 1969 to 1974, followed by a long-term statistically significant decline phase from 1974 to the $1990 \mathrm{~s}$. However, the trend of annual WS in the upper region has only a statistically significant decline phase from 1961 to 2014. There are significant decreasing 

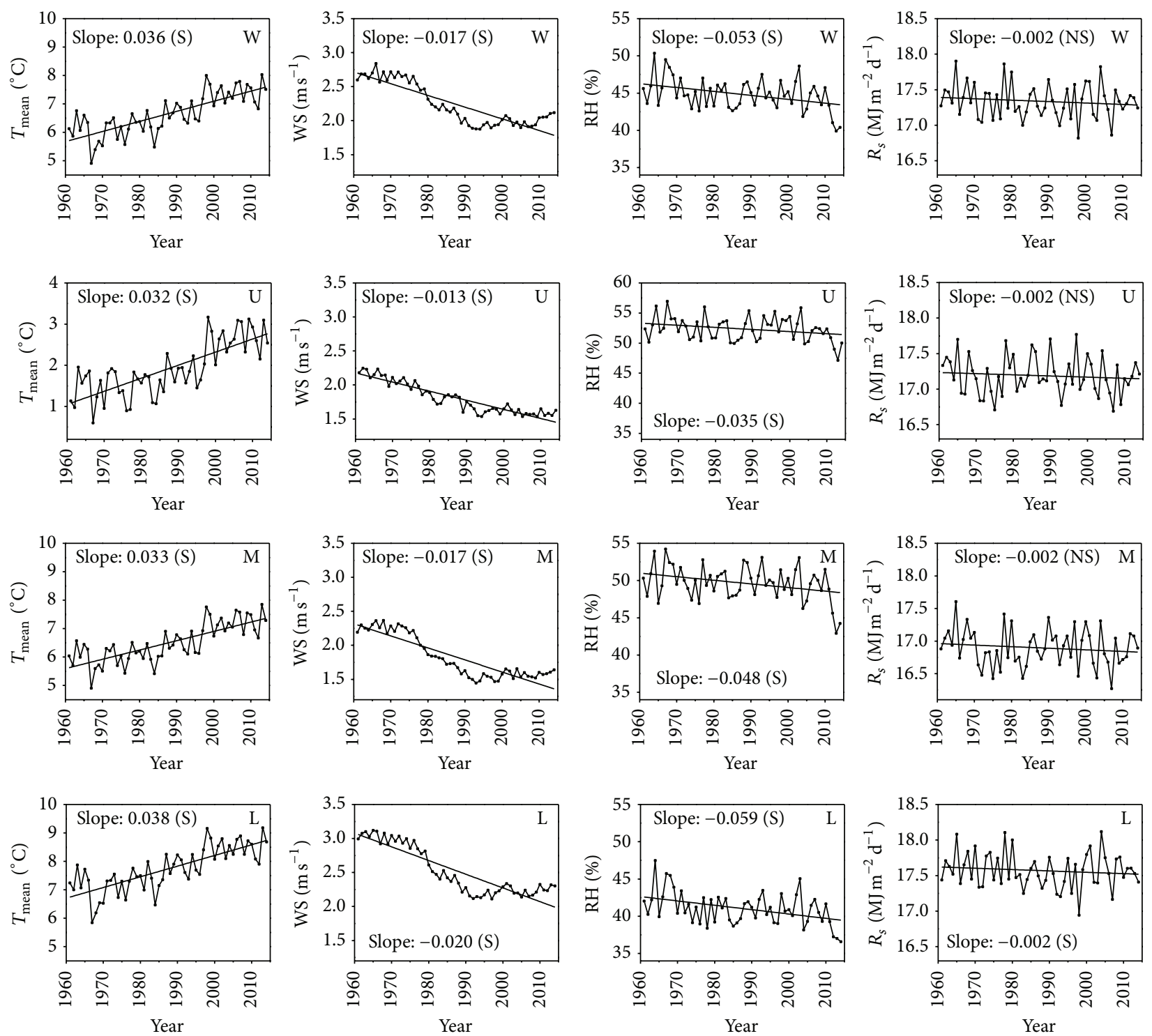

FIGURE 8: Trends of annual $T_{\text {mean }}$, WS, RH, and $R_{s}$ for the upper (U), middle (M), and lower $(\mathrm{L})$ region and the whole basin (W). $S$ indicates that the trend is statistically significant, and NS indicates that the trend is not significant at the 0.05 level.

trends for the upper, middle, and lower regions, with change rates of $-0.13 \mathrm{~m} \mathrm{~s}^{-1} \cdot 10 \mathrm{yr}^{-2},-0.17 \mathrm{~m} \mathrm{~s}^{-1} \cdot 10 \mathrm{yr}^{-2}$, and $-0.20 \mathrm{~m} \mathrm{~s}^{-1} \cdot 10 \mathrm{yr}^{-2}$, respectively.

The mean annual $\mathrm{RH}$ in the lower, middle, and upper regions is $41 \% \mathrm{yr}^{-1}, 50 \% \mathrm{yr}^{-1}$, and $52 \% \mathrm{yr}^{-1}$, respectively. During 1961 and 2014, decreasing trends in the upper and middle regions are not statistically significant, whereas the changes in annual RH in the lower region and whole basin have significant decreasing trends. Therefore, the changes in $\mathrm{RH}$ across the whole basin are mainly affected by the trend of $\mathrm{RH}$ in the lower region.

The change of annual $R_{s}$ for the different regions has no significant decreasing trend during the 54-year period, whereas the interannual oscillations of $R_{s}$ are clearer than those of RH.
4.4. Variations of the Sensitivity Coefficients. Mean daily sensitivity coefficients for major meteorological factors that exhibit large fluctuations during a year (Figure 11). Although annual $T_{\max }$ and $T_{\min }$ have the same trend, the variations of $S_{T_{\max }}$ and $S_{T_{\min }}$ are different. $S_{T_{\max }}$ gradually increases from negative to positive at first and then decreases from positive to negative and achieves a larger and stable peak value during May and August (Figure 9(a)). The daily variation patterns of $S_{T_{\min }}$ have a unimodal distribution, and the peak occurs on the 200th day of the year (Figure $9(\mathrm{~b})$ ). $S_{T_{\min }}$ and $S_{T_{\min }}$ are positive during summer, and the former is larger than the latter. $S_{T_{\max }}$ and $S_{T_{\min }}$ are negative during winter days, and the latter is smaller than the former. Thus, $\mathrm{ET}_{0}$ is sensitive to $T_{\max }$ in summer but $T_{\min }$ in winter. The value of $S_{T_{\max }}$ is greater in the lower region than in the other two regions. $S_{T_{\min }}$ for the 

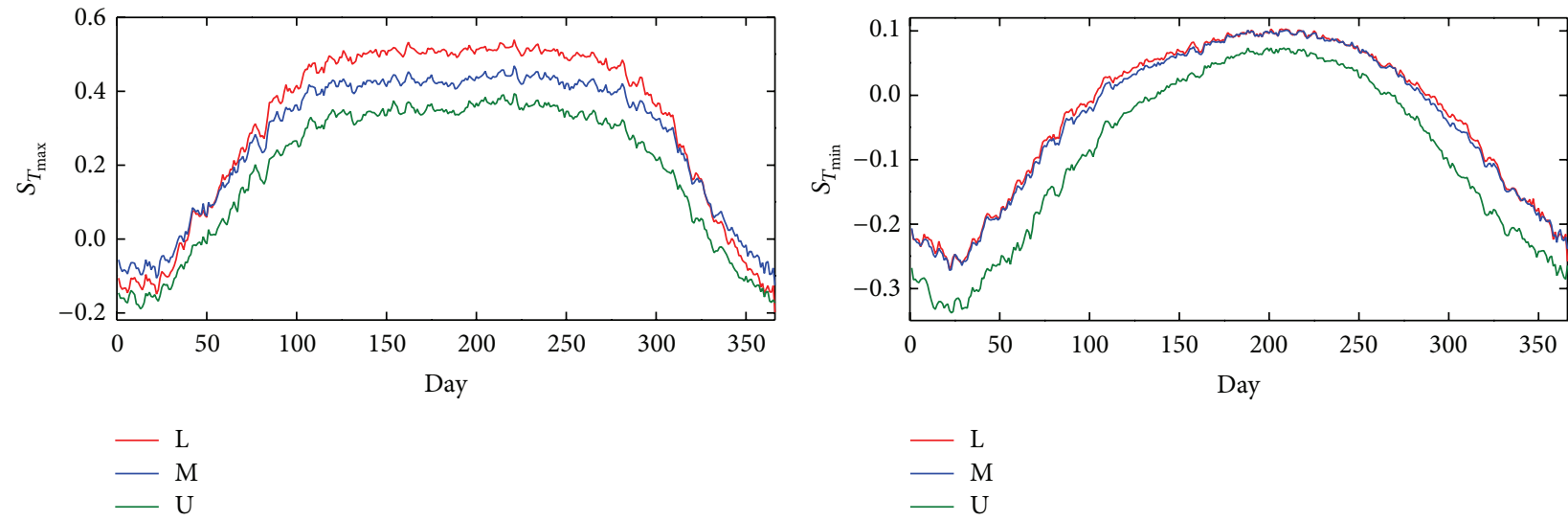

(a)
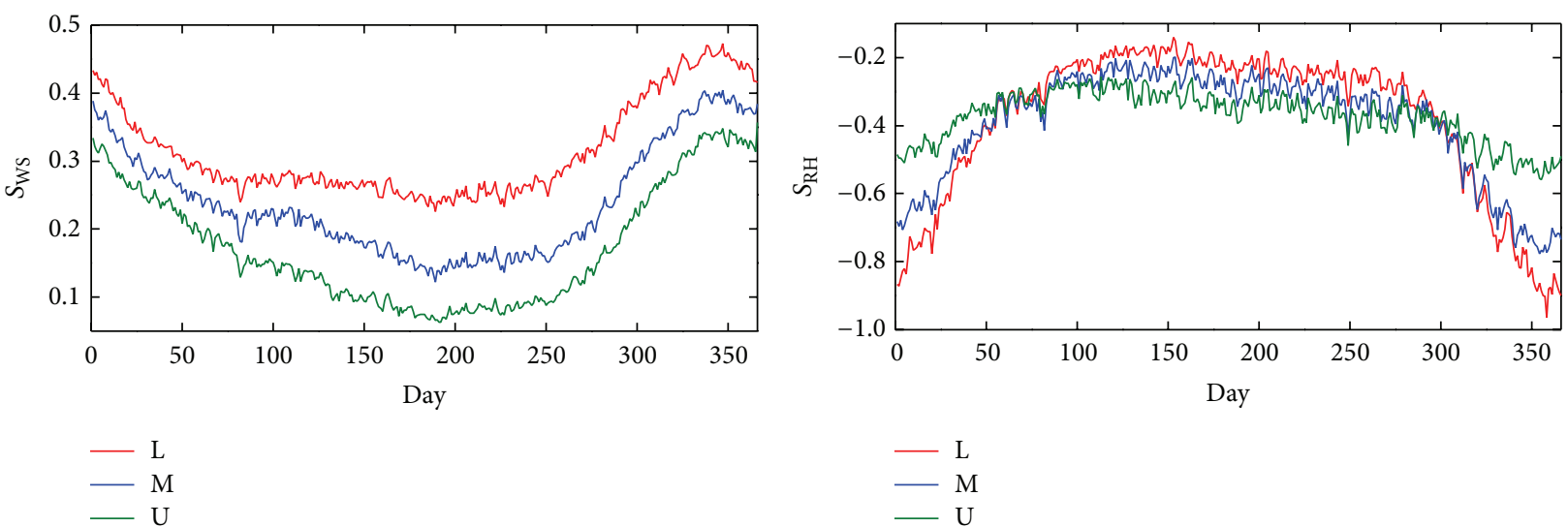

(c)
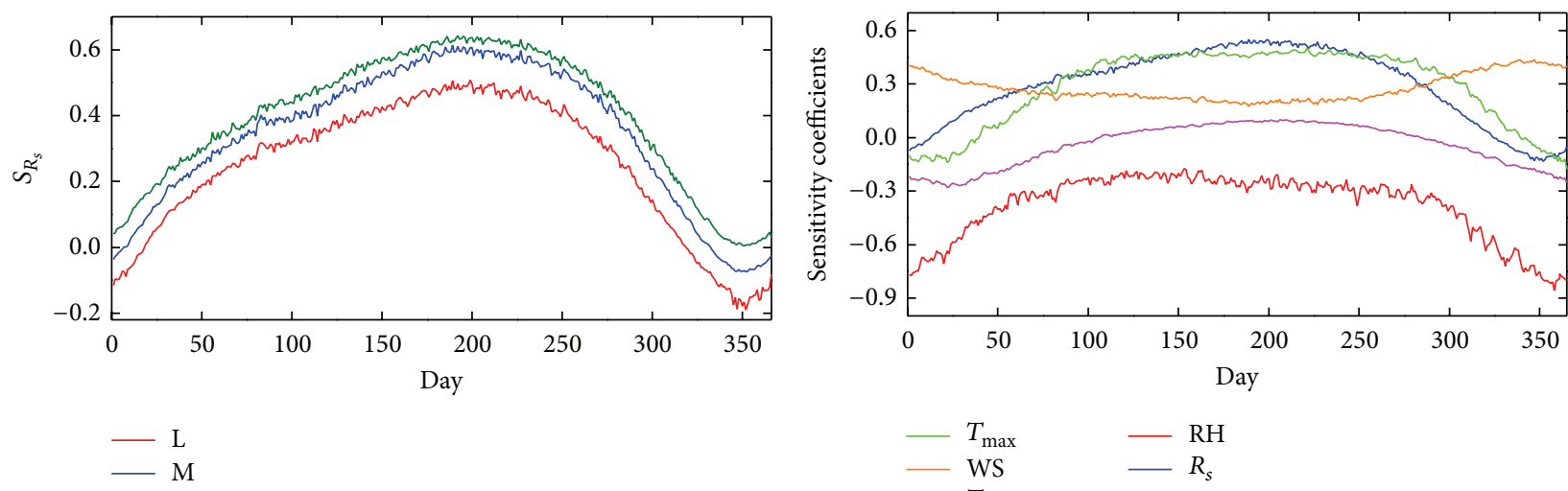

(e)

(f)

FigURE 9: Mean daily sensitivity coefficients for maximum temperature (a), minimum temperature (b), wind speed (c), relative humidity (d), and shortwave radiation (e) in the upper (U), middle (M), and lower (L) regions of the HRB. (f) Comparison of the mean daily sensitivity coefficients for major meteorological factors in the whole basin.

middle and lower regions is almost the same and is greater than that in the upper region.

The values of $S_{\mathrm{WS}}$ in the three regions are positive throughout the year. $\mathrm{ET}_{0}$ is most sensitive to WS in the beginning and end of a year but is insensitive to WS in summer (Figure 9(c)). The variation patterns of $S_{\text {WS }}$ for the three regions are the same. The values of $S_{\mathrm{Ws}}$ for the three regions have significant differences during a year. The value in the lower region is the largest; thus, $\mathrm{ET}_{0}$ is more sensitive to WS in the lower region than in the other two regions.

Relatively strong negative sensitivity coefficients were obtained for RH (Figure 9(d)). $\mathrm{ET}_{0}$ is less sensitive to $\mathrm{RH}$ in 

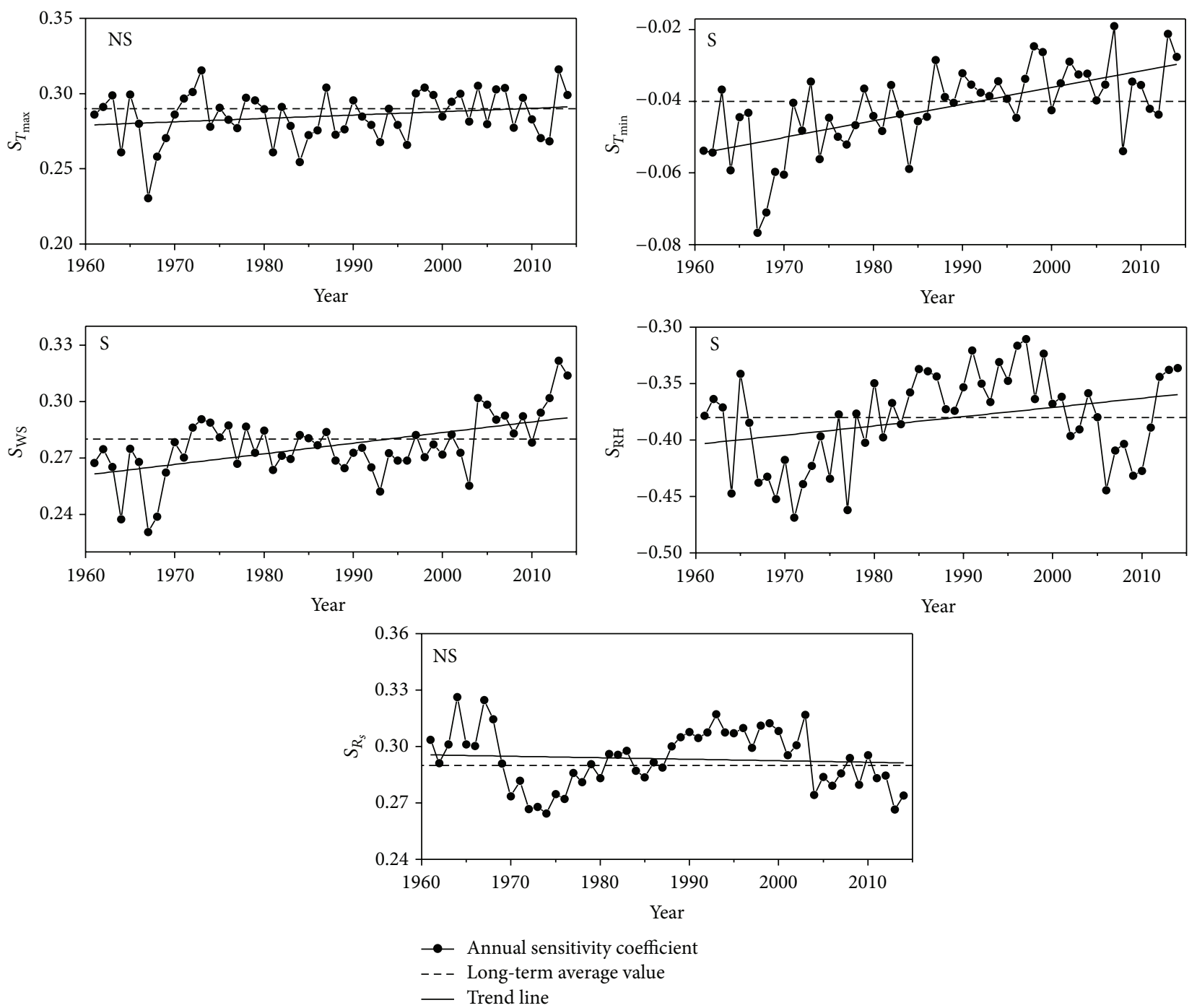

Figure 10: Interannual variations of sensitivity of $\mathrm{ET}_{0}$ in relation to $T_{\max }, T_{\min }$, WS, RH, and $R_{s}$.

the winter for the upper region compared with the two other regions. However, $\mathrm{ET}_{0}$ is more negative sensitive to $\mathrm{RH}$ in the lower region during April and September.

The daily variation patterns of $S_{R_{s}}$ agree with those of shortwave radiation (Figure $9(\mathrm{e})$ ). $\mathrm{ET}_{0}$ is insensitive to $R_{s}$ in winter, and $S_{R_{s}}$ increases and achieves its maximum value in summer. The variations of $S_{R_{s}}$ for the three regions show similar patterns, whereas $S_{R_{s}}$ in the lower region is significantly less than that in the upper and middle regions. The variation of daily $S_{R_{s}}$ and $S_{\text {Ws }}$ appears to be an opposite pattern during a year. Similar findings were reported by Gong et al. [19]. $S_{T_{\max }}$ and $S_{R_{s}}$ have a similar variation pattern, whereas $S_{T_{\min }}$ and $S_{\mathrm{WS}}$ appear to have opposite patterns. $\mathrm{RH}$ is the most sensitive factor and WS and $T_{\min }$ are the least sensitive factors in the whole basin throughout the year.

Figure 10 shows the interannual variations of annual sensitivity coefficients from 1961 to 2014. The variation of annual $S_{\mathrm{WS}}$ has a significant increasing trend, whereas the absolute values of $S_{T_{\min }}$ and $S_{\mathrm{RH}}$ show that they have statistically significant decreasing trends during 1961 and
2014. $\mathrm{ET}_{0}$ becomes more sensitive to WS but less sensitive to $T_{\min }$ and $\mathrm{RH}$. The annual $S_{T_{\max }}$ and $S_{R_{s}}$ have increasing and decreasing trends, respectively, but their trends are not statistically significant during the period of 1961-2014. This shows that the relative changes of the meteorological factors $T_{\min }$ and $R_{s}$ and the relative change of $\mathrm{ET}_{0}$ maintain a stable ratio [41].

Figure 11 describes the spatial patterns of the sensitivity coefficients of $\mathrm{ET}_{0}$ to the major meteorological factors across the whole HRB. The mean annual values of sensitivity for $T_{\text {max }}, T_{\text {min }}, \mathrm{WS}, \mathrm{RH}$, and $R_{s}$ are $0.28,-0.04,0.27,-0.38$, and 0.29 at the basin scale, respectively. $\mathrm{RH}$ is the most sensitive factor, and $T_{\min }$ is less sensitive to $\mathrm{ET}_{0}$ over the whole basin. It seems that $S_{T_{\max }}$ and $S_{T_{\min }}$ have similar spatial patterns, whereas spatial distributions of the absolute values of $S_{T_{m a}}$ and $S_{T_{\min }}$ are opposite due to the negative sign of $S_{T_{\min }}$. Overall, there are three different spatial distributions for the five meteorological factors. (1) $S_{T_{\max }}$ and $S_{\mathrm{WS}}$ have a similar spatial pattern, increasing from the south to the north of the basin with significant spatial gradients. (2) The spatial patterns of 

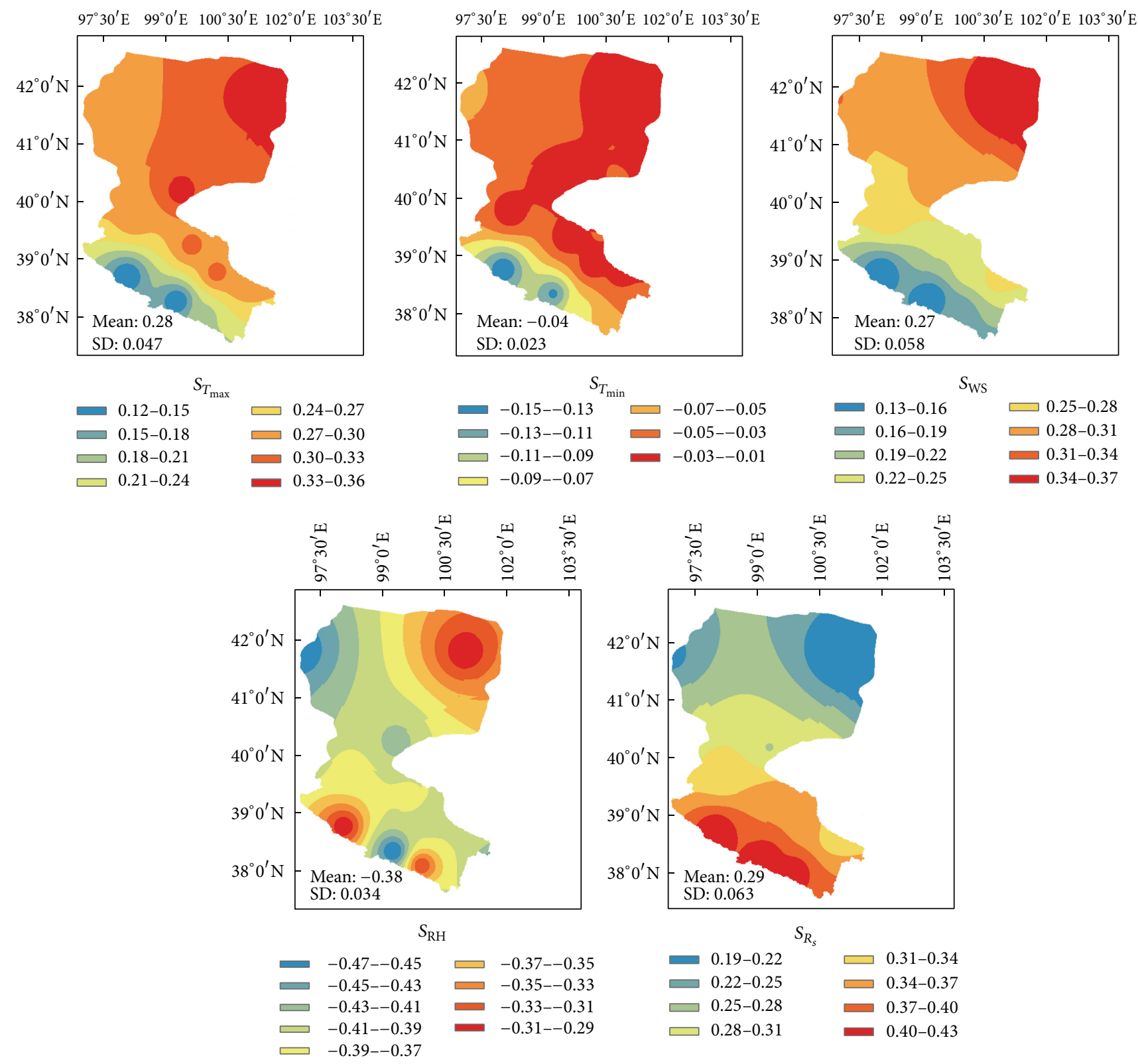

FIGURE 11: Spatial distribution of the mean annual sensitivity coefficients for $\mathrm{ET}_{0}$ to the major meteorological factors $\left(T_{\max }, T_{\min }\right.$, WS, RH, and $R_{s}$ ) during 1961-2014.

$S_{T_{\min }}$ and $S_{R_{s}}$ are similar, and the sensitivity for the two factors decreases from the upper region to the lower region. (3) The spatial variation of $S_{\mathrm{RH}}$ has no significant gradient from the lower region to the upper region.

4.5. Contribution of the Trends of the Meteorological Factors to That of $E T_{0}$. The sensitivity coefficient describes the response of $\mathrm{ET}_{0}$ to changes in meteorological factors but is not able to reflect change magnitude in $\mathrm{ET}_{0}$ caused by meteorological factors. Namely, $\mathrm{ET}_{0}$ change is strongly sensitive to a meteorological factor, but the meteorological factor must not cause a significant change in $\mathrm{ET}_{0}$. This is because, other than the sensitivity coefficients, changes in $\mathrm{ET}_{0}$ are influenced by changes in meteorological factors as well. Consequently, (15) is used to diagnose the contribution of meteorological factors to $\mathrm{ET}_{0}$ changes.

As shown in Figure 12, the relative changes of monthly, seasonal, and annual $\mathrm{ET}_{0}$ calculated using (15) well fit those of the actual $\mathrm{ET}_{0}$ from observed data. This result illustrates that sensitivity coefficients and changes in meteorological factors could be used to analyze the contribution of one or more meteorological factors to $\mathrm{ET}_{0}$ changes in the HRB.

Figure 13 shows the contributions of meteorological factor changes to relative changes in annual and seasonal $\mathrm{ET}_{0}$ for the 9 stations in the HRB during 1961-2014. WS is the largest contributor to $\mathrm{ET}_{0}$ change among meteorological factors in the middle and lower regions. The decreasing trends of WS cause $\mathrm{ET}_{0}$ decreases, with relative changes in $\mathrm{ET}_{0}$ of $-3 \%$ 


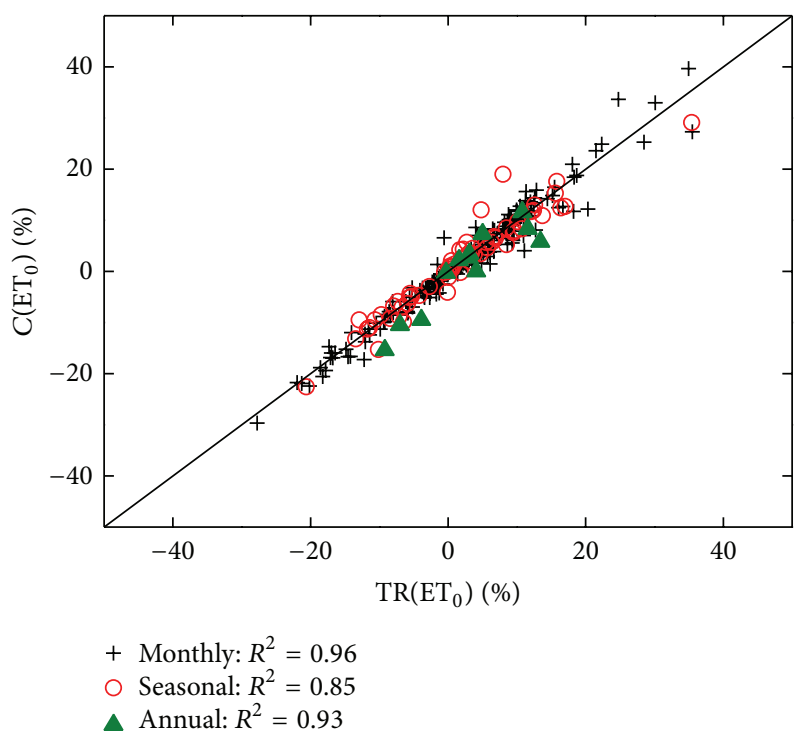

FIgure 12: Relationship of $C\left(\mathrm{ET}_{0}\right)$ to $\mathrm{TR}\left(\mathrm{ET}_{0}\right)$ at different time scales for all stations in the HRB. $C\left(\mathrm{ET}_{0}\right)$ is the sum of the relative change of $\mathrm{ET}_{0}$ contributed by changes in meteorological factors using (15). $\mathrm{TR}\left(\mathrm{ET}_{0}\right)$ is the long-term relative change of $\mathrm{ET}_{0}$ from the observed data.

to $-18 \%$, corresponding to changes of -30 to $-250 \mathrm{~mm}$. However, $T_{\min }$ and $R_{s}$ trends from 1961 to 2014 have little influence on the changes in $\mathrm{ET}_{0}$ for the middle-lower regions. For the upper region, the trends of $T_{\max }$ and $T_{\min }$ for all stations significantly increase $\mathrm{ET}_{0}$, and relative changes of $\mathrm{ET}_{0}$ are between $2.3 \%$ and $3.2 \%$, corresponding to changes of 19 to $26 \mathrm{~mm}$. The positive effects of WS and $\mathrm{RH}_{\text {on }} \mathrm{ET}_{0}$ change are similar to air temperature, which cannot be ignored for station U3.

The contribution of the seasonal change of meteorological factors to $\mathrm{ET}_{0}$ change is similar to that at an annul scale. WS is still the dominant contributor to $\mathrm{ET}_{0}$ change for the middle-lower regions at all seasons. The relative changes of $\mathrm{ET}_{0}$ caused by WS change are greater than $5 \%$ for most stations in the middle and lower regions, whereas the relative changes of $\mathrm{ET}_{0}$ caused by other factors are less than $5 \%$. The trends of seasonal $T_{\max }$ and $T_{\min }$ still result in an increase in $\mathrm{ET}_{0}$ for the upper region. However, there are differences for the contribution levels of each meteorological factor in different seasons and regions. For example, the trends of $R_{s}$ for stations $\mathrm{U} 1, \mathrm{U} 2$, and M1 have more significant contributions to the changes of $\mathrm{ET}_{0}$ only in summer, whereas the $R_{s}$ trends for all stations have little effect on the changes of $\mathrm{ET}_{0}$ in other seasons. Moreover, the $T_{\min }$ trends in lower regions do not contribute to changes in $\mathrm{ET}_{0}$ in autumn, whereas the contribution of $T_{\min }$ to $\mathrm{ET}_{0}$ change is strong in the other three seasons. RH and WS for station U3 have similar effects on $\mathrm{ET}_{0}$ change, for which the effect is stronger in summer than that in other regions.

\section{Discussion}

This paper carefully and thoroughly analyzed the trends and spatial variations of the annual and seasonal $\mathrm{ET}_{0}$ for different regions over the HRB. The spatial patterns of annual and seasonal $\mathrm{ET}_{0}$ during the last 54 years in this study are consistent with the previous studies $[34,35]$. However, the overall increasing trend $\left(2.01 \mathrm{~mm} \cdot 10 \mathrm{yr}^{-2}\right)$ of annual $\mathrm{ET}_{0}$ for the whole basin in this paper is different from the significant decreasing trend reported by previous studies [29, 30]. After serious comparison and analysis, the causes of the differences come from inconsistent study areas and from differences in the data time series, treatment of missing data, and analysis methods. (i) Because the lower region of the HRB is the desert area and is difficult to fix the basin divides, four different basin areas have been defined by the Yellow River Conservancy Commission during different periods. The basin area defined most recently in 2005 is larger than the basin areas defined in 1985, 1995, and 2000 and can better describe the hydrological characteristics, especially for the lower region of the basin. This study adopted the latest basin area data defined in 2005, and previous studies adopted the earlier basin area data defined in 1995. (ii) Different data time series may result in different trends of annual $\mathrm{ET}_{0}$. The trends of annual and seasonal $\mathrm{ET}_{0}$ calculated by the data series of 1959-1999 or 1961-2000 were earlier and shorter than the data series of 1961-2014 in this study. This latest data series, covering more than 50 years of climate stage and data quality during this latest period, is more reliable and is without missing data. (iii) Because meteorological stations are scarce in the inland arid basin in China, the stations around the basin must be considered to increase the precision of calculation of regional $\mathrm{ET}_{0}$. Clearly, the results obtained using only the 10 stations in the previous studies are less reliable than those using 16 stations related to the basin.

Equation (15) was used to assess the contribution of meteorological factors to $\mathrm{ET}_{0}$ trends. Figure 12 shows that correlation of the estimated and the actual relative changes of $\mathrm{ET}_{0}$ are very good, whereas the correlation coefficients decrease with increasing time scales from monthly scale to annual scale. This illustrated that the accuracy of (15) decreases with increasing time scale. The error sources of (15) are that (i) the five major meteorological factors cannot completely cover all impact factors of the FAO P-M equation; (ii) the selected factors interact with each other and are not totally independent; and (iii) the annual averaging variations of the daily sensitivity coefficient could produce different offsets to $\mathrm{ET}_{0}$ changes contributed by different meteorological factors.

\section{Summary}

In arid regions, investigating the causes of reference evapotranspiration $\left(\mathrm{ET}_{0}\right)$ change is important for understanding hydroclimatic change and the response of ecoenvironment. The Heihe River Basin (HRB), the second largest inland river basin in China, is divided into the upper, middle, and lower subregions to diagnose the causes of $\mathrm{ET}_{0}$ changes in different dryness environment.

First, the $\mathrm{ET}_{0}$ changes for the $\mathrm{HRB}$ were obtained by FAO P-M method and meteorological data series from 16 stations during 1961-2014. The seasonal and annual $\mathrm{ET}_{0}$ have no significant increasing trends for the whole basin, whereas 

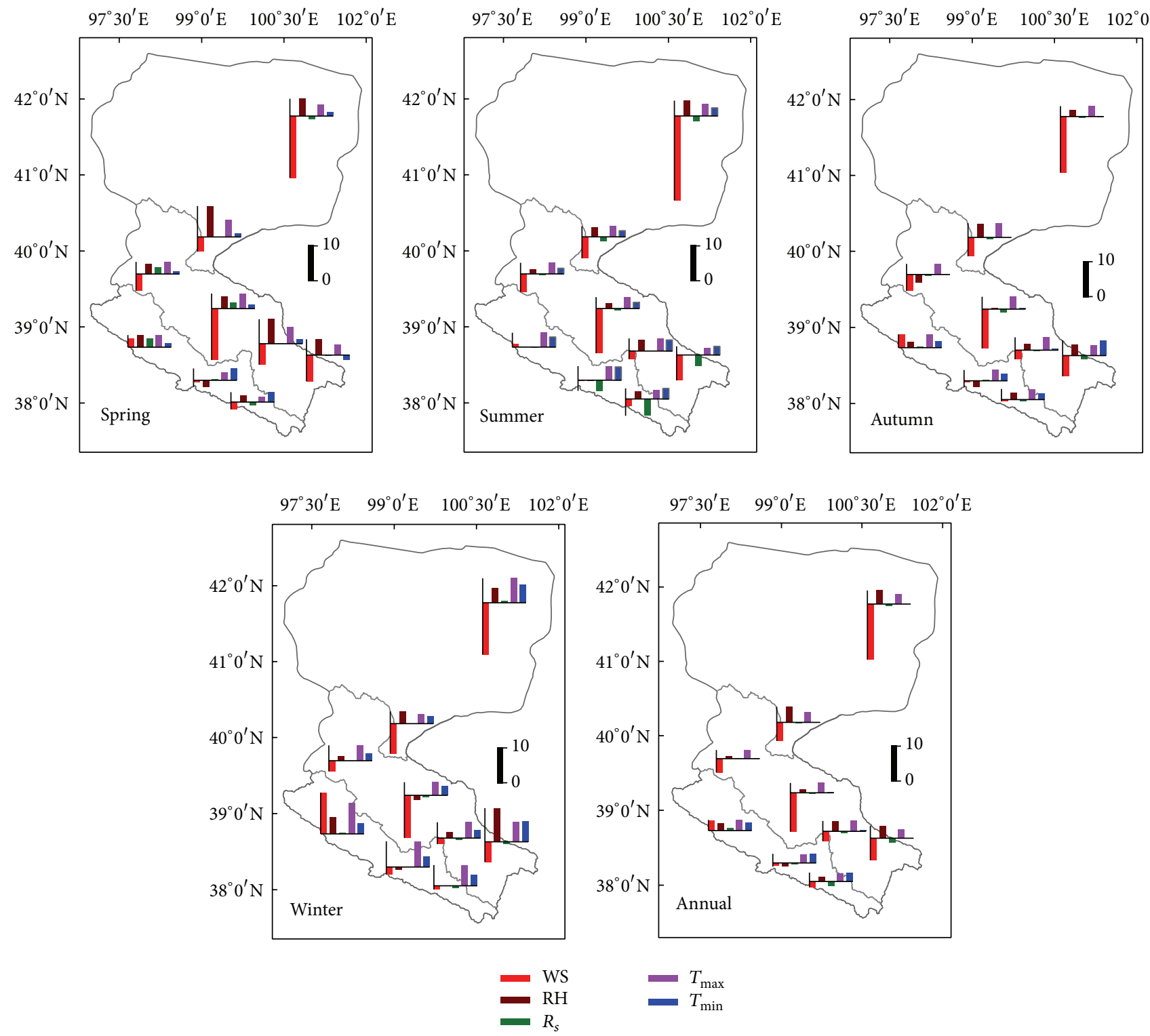

FIGURE 13: Contributions of meteorological factor changes to relative changes in $\mathrm{ET}_{0}$ at annual and seasonal time scales for the stations in the $\mathrm{HRB}$. An upward bar means that the factor trend causes a positive change in $\mathrm{ET}_{0}$, and a downward bar means that the factor trend causes a negative change in $\mathrm{ET}_{0}$.

there is a clear increasing spatial gradient from the upper region to the lower region.

Second, the dimensionless sensitivity analysis showed that relative humidity is most sensitive to $\mathrm{ET}_{0}$ change and negative, followed by maximum temperature and shortwave radiation but with positive sensitivity. The sensitivity of minimum temperature is weakest and negative.

Finally, to quantify the influence magnitude of the major meteorological factors on $\mathrm{ET}_{0}$ changes, an approach to integrating the sensitivity and changes of meteorological factors is proposed. Contribution analysis showed that wind speed is the dominant factor to cause the decrease of $\mathrm{ET}_{0}$ for the middle and lower regions. And the maximum and minimum temperatures are the main contributors to the increasing trends of $\mathrm{ET}_{0}$ for the upper region. Therefore, the $\mathrm{ET}_{0}$ changes are mainly affected by aerodynamic factors rather than radiative factors as dryness increase.

\section{Conflict of Interests}

The authors declare that there is no conflict of interests regarding the publication of this paper.

\section{Acknowledgments}

This research was supported by the National Natural Science Foundation of China (41271049) and the National Basic Research Program of China (2009CB421305). The authors thank the National Climate Center of China for offering 
the meteorological data used in this study. The first author appreciates the constructive suggestions of Professor Mo Xingguo, Associate Professor Sang Yanfang, and Doctor Zhang Dan for the improvement of this paper. All authors wish to acknowledge the editor and anonymous reviewers for their patience and the detailed and helpful comments to the original paper.

\section{References}

[1] P. G. Oguntunde, J. Friesen, N. van de Giesen, and H. H. G. Savenije, "Hydroclimatology of the Volta river basin in west Africa: trends and variability from 1901 to 2002," Physics and Chemistry of the Earth, vol. 31, no. 18, pp. 1180-1188, 2006.

[2] C. Matsoukas, N. Benas, N. Hatzianastassiou, K. G. Pavlakis, M. Kanakidou, and I. Vardavas, "Potential evaporation trends over land between 1983-2008: driven by radiative fluxes or vapourpressure deficit?" Atmospheric Chemistry and Physics, vol. 11, no. 15, pp. 7601-7616, 2011.

[3] K. Wang and R. E. Dickinson, "A review of global terrestrial evapotranspiration: observation, modeling, climatology, and climatic variability," Reviews of Geophysics, vol. 50, no. 2, 2012.

[4] V. S. Golubev, J. H. Lawrimore, P. Y. Groisman et al., "Evaporation changes over the contiguous United States and the former USSR: a reassessment," Geophysical Research Letters, vol. 28, no. 13, pp. 2665-2668, 2001.

[5] X. Liu, Y. Luo, D. Zhang, M. Zhang, and C. Liu, "Recent changes in pan-evaporation dynamics in China," Geophysical Research Letters, vol. 38, no. 13, 2011.

[6] D. H. Burn and N. M. Hesch, "Trends in evaporation for the Canadian prairies," Journal of Hydrology, vol. 336, no. 1-2, pp. 61-73, 2007.

[7] M. L. Roderick and G. D. Farquhar, "Changes in Australian pan evaporation from 1970 to 2002," International Journal of Climatology, vol. 24, no. 9, pp. 1077-1090, 2004.

[8] N. Chattopadhyay and M. Hulme, "Evaporation and potential evapotranspiration in India under conditions of recent and future climate change," Agricultural and Forest Meteorology, vol. 87, no. 1, pp. 55-73, 1997.

[9] J. Asanuma, "Long-term trend of pan evaporation measurements in Japan and its relevance to the variability of the hydrological cycle," Tenki, vol. 51, no. 9, pp. 667-678, 2004.

[10] A.-E. Croitoru, A. Piticar, C. S. Dragotă, and D. C. Burada, "Recent changes in reference evapotranspiration in Romania," Global and Planetary Change, vol. 111, pp. 127-136, 2013.

[11] S. Saadi, M. Todorovic, L. Tanasijevic, L. S. Pereira, C. Pizzigalli, and P. Lionello, "Climate change and Mediterranean agriculture: impacts on winter wheat and tomato crop evapotranspiration, irrigation requirements and yield," Agricultural Water Management, vol. 147, pp. 103-115, 2015.

[12] A. Sharifi and Y. Dinpashoh, "Sensitivity analysis of the penman-monteith reference crop evapotranspiration to climatic variables in Iran," Water Resources Management, vol. 28, no. 15, pp. 5465-5476, 2014.

[13] S. M. Vicente-Serrano, C. Azorin-Molina, A. Sanchez-Lorenzo et al., "Reference evapotranspiration variability and trends in Spain, 1961-2011," Global and Planetary Change, vol. 121, pp. 2640, 2014.

[14] M. Gocic and S. Trajkovic, "Analysis of trends in reference evapotranspiration data in a humid climate," Hydrological Sciences Journal, vol. 59, no. 1, pp. 165-180, 2014.
[15] M. Valipour, "Importance of solar radiation, temperature, relative humidity, and wind speed for calculation of reference evapotranspiration," Archives of Agronomy and Soil Science, vol. 61, no. 2, pp. 239-255, 2015.

[16] R. G. Allen, L. S. Pereira, D. Raes, and M. Smith, Crop Evapotranspiration: Guidelines for Computing Crop Water Requirements, vol. 56 of FAO Irrigation and Drainage Paper, Food and Agric, Organ, Rome, Italy, 1998.

[17] M. M. Heydari, R. Aghamajidi, G. Beygipoor, and M. Heydari, "Comparison and evaluation of 38 equations for estimating reference evapotranspiration in an arid region," Fresenius Environmental Bulletin, vol. 23, no. 8, pp. 1985-1996, 2014.

[18] K. E. Saxton, "Sensitivity analyses of the combination evapotranspiration equation," Agricultural Meteorology, vol. 15, no. 3, pp. 343-353, 1975.

[19] L. Gong, C.-Y. Xu, D. Chen, S. Halldin, and Y. D. Chen, "Sensitivity of the Penman-Monteith reference evapotranspiration to key climatic variables in the Changjiang (Yangtze River) basin," Journal of Hydrology, vol. 329, no. 3-4, pp. 620-629, 2006.

[20] S. M. Vicente-Serrano, C. Azorin-Molina, A. Sanchez-Lorenzo et al., "Sensitivity of reference evapotranspiration to changes in meteorological parameters in Spain (1961-2011)," Water Resources Research, vol. 50, no. 11, pp. 8458-8480, 2014.

[21] R. K. Goyal, "Sensitivity of evapotranspiration to global warming: a case study of arid zone of Rajasthan (India)," Agricultural Water Management, vol. 69, no. 1, pp. 1-11, 2004.

[22] Y. Zhao, X. Zou, J. Zhang et al., "Spatio-temporal variation of reference evapotranspiration and aridity index in the Loess Plateau Region of China, during 1961-2012," Quaternary International, vol. 349, pp. 196-206, 2014.

[23] B. Wang and G. Li, "Quantification of the reasons for reference evapotranspiration changes over the Liaohe Delta, Northeast China," Scientia Geographica Sinica, vol. 34, no. 10, pp. 12331238, 2014 (Chinese).

[24] H. Xie and X. Zhu, "Reference evapotranspiration trends and their sensitivity to climatic change on the Tibetan Plateau (1970-2009)," Hydrological Processes, vol. 27, no. 25, pp. 36853693, 2013.

[25] X. Liu, H. Zheng, C. Liu, and Y. Cao, "Sensitivity of the potential evapotranspiration to key climatic variables in the Haihe River Basin," Resources Science, vol. 31, no. 9, pp. 1470-1476, 2009 (Chinese).

[26] G. Papaioannou, G. Kitsara, and S. Athanasatos, "Impact of global dimming and brightening on reference evapotranspiration in Greece," Journal of Geophysical Research: Atmospheres, vol. 116, no. 9, Article ID D09107, 2011.

[27] C.-S. Rim, "A sensitivity and error analysis for the penman evapotranspiration model," KSCE Journal of Civil Engineering, vol. 8, no. 2, pp. 249-254, 2004.

[28] Q. Liu, Z. Yang, B. Cui, and T. Sun, “The temporal trends of reference evapotranspiration and its sensitivity to key meteorological variables in the Yellow River Basin, China," Hydrological Processes, vol. 24, no. 15, pp. 2171-2181, 2010.

[29] N. Ma, N. Wang, P. Wang, Y. Sun, and C. Dong, “Temporal and spatial variation characteristics and quantification of the affect factors for reference evapotranspiration in Heihe River basin," Journal of Natural Resources, vol. 27, no. 6, pp. 975-989, 2012 (Chinese).

[30] J. Zhao, Z. Xu, and D. Zuo, "Spatiotemporal variation of potential evapotranspiration in the Heihe River basin," Journal of Beijing Normal University. Natural Science, vol. 49, no. 2-3, pp. 164-169, 2013 (Chinese). 
[31] C.-Y. Xu, L. Gong, T. Jiang, D. Chen, and V. P. Singh, "Analysis of spatial distribution and temporal trend of reference evapotranspiration and pan evaporation in Changjiang (Yangtze River) catchment," Journal of Hydrology, vol. 327, no. 1-2, pp. 81-93, 2006.

[32] A. Thomas, "Spatial and temporal characteristics of potential evapotranspiration trends over China," International Journal of Climatology, vol. 20, no. 4, pp. 381-396, 2000.

[33] C. Liu, D. Zhang, X. Liu, and C. Zhao, "Spatial and temporal change in the potential evapotranspiration sensitivity to meteorological factors in China (1960-2007)," Journal of Geographical Sciences, vol. 22, no. 1, pp. 3-14, 2012.

[34] H. B. Mann, "Nonparametric tests against trend," Econometrica, vol. 13, no. 3, pp. 245-259, 1945.

[35] M. G. Kendall, Rank Correlation Methods, Griffin, Oxford, UK, 1948.

[36] S. Yue and P. Pilon, "A comparison of the power of the $t$ test, Mann-Kendall and bootstrap tests for trend detection," Hydrological Sciences Journal, vol. 49, no. 1, pp. 21-37, 2004.

[37] R. M. Hirsch, J. R. Slack, and R. A. Smith, "Techniques of trend analysis for monthly water quality data," Water Resources Research, vol. 18, no. 1, pp. 107-121, 1982.

[38] R. M. Hirsch and J. R. Slack, "A nonparametric trend test for seasonal data with serial dependence," Water Resources Research, vol. 20, no. 6, pp. 727-732, 1984.

[39] A. G. Smajstrla, F. S. Zazueta, and G. M. Schmidt, "Sensitivity of potential evapotranspiration to four climatic variables in Florida," Proceedings-Soil and Crop Science Society of Florida, vol. 46, 1987, paper presented at.

[40] P. Greve, L. Gudmundsson, B. Orlowsky, and S. I. Seneviratne, "Introducing a probabilistic Budyko framework," Geophysical Research Letters, vol. 42, no. 7, pp. 2261-2269, 2015.

[41] H. Zheng, X. Liu, C. Liu, X. Dai, and R. Zhu, "Assessing contributions to panevaporation trends in Haihe River Basin, China," Journal of Geophysical Research: Atmospheres, vol. 114, no. 24, Article ID D24105, 2009. 

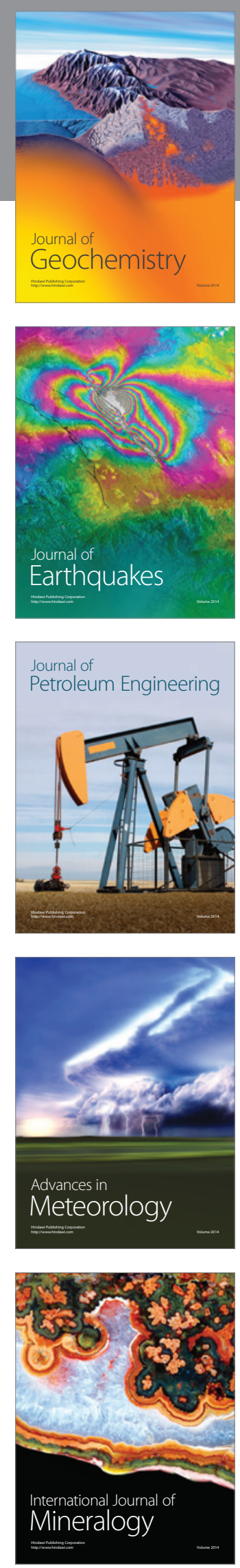
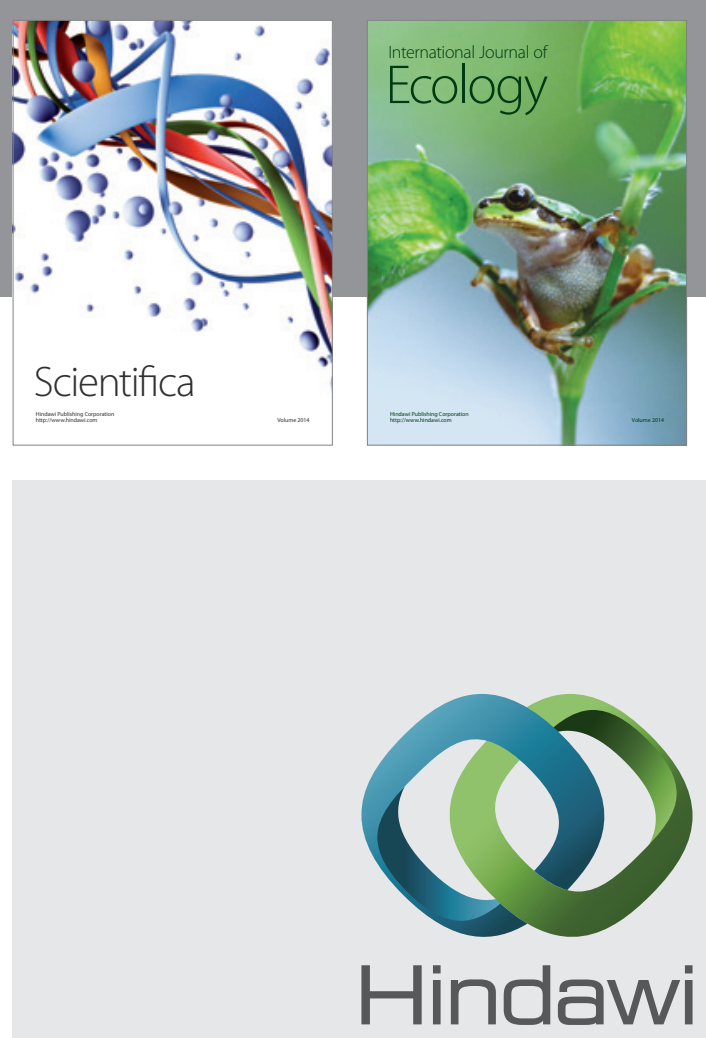

Submit your manuscripts at

http://www.hindawi.com
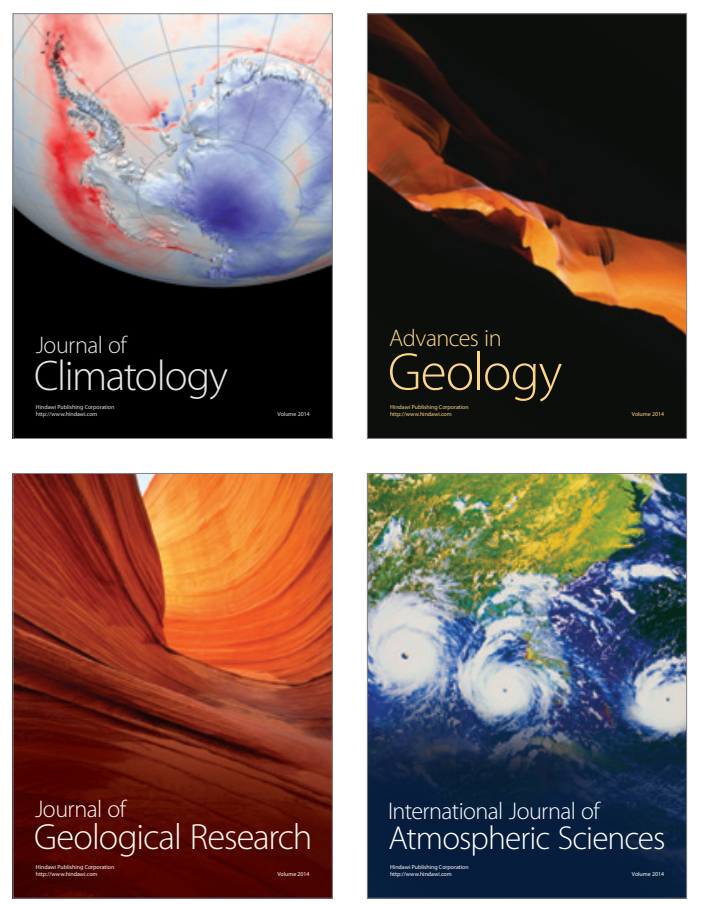

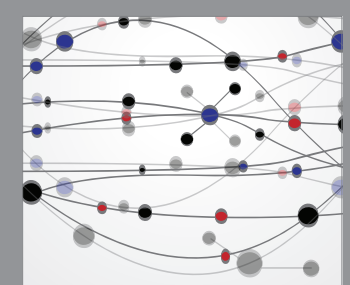

The Scientific

\section{World Journal}
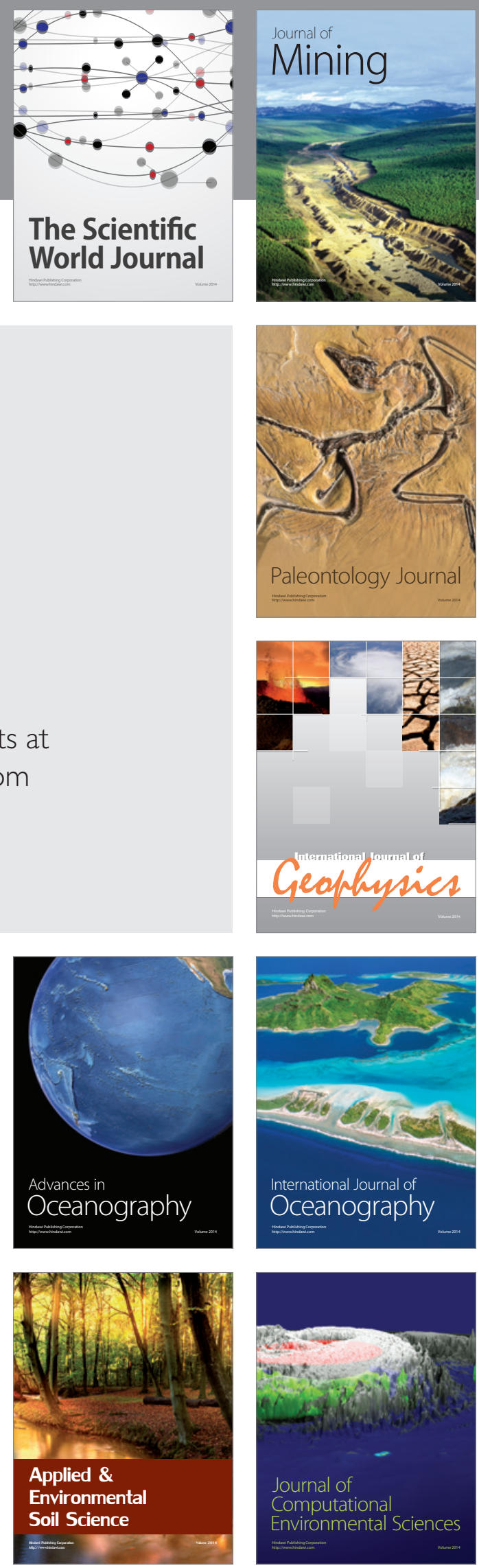